The Federal Reserve BanK of Kansas City ECONOMIC RESEARCH DEPARTMENT

Do We Really Know How Inflation Targeters Set Interest Rates?

Marcela Meirelles Aurelio

July 2005

RWP $05-02$ 


\title{
Do We REALly KNOW HOW INFLATION TARGETERS SET INTEREST RATES?
}

\author{
Marcela Meirelles Aurelio*
}

July 2005

RWP 05-02

\begin{abstract}
In inflation targeting (IT) regimes, the Monetary Authority announces an explicit objective, the target for inflation. However, other objectives that possibly conflict with the inflation goal are present, such as keeping output close to its potential level and the stability of financial markets. This multiplicity of objectives has spurred a debate on whether inflation targeting really provides a transparent framework for monetary policy. This question is addressed in this paper, focusing on the experience of six countries that adopted IT. The empirical investigation is based on a variety of data sets (including real time data and Central Bank's forecasts), as well as on alternative forward-looking reaction functions. The main finding is that, if transparency is interpreted as the short run predictability of policy actions, consistent with the announced inflation goal, then most of the IT regimes here examined are remarkably transparent. However, this is not necessarily true if a more broad interpretation of transparency is required. The data also reveals a certain degree of heterogeneity across countries and time, and therefore recommends caution with respect to general statements regarding the properties of IT regimes.
\end{abstract}

Keywords: monetary policy transparency, inflation targeting, forward-looking interest rate rules, forecasting

JEL classification: E52, E61, F41, F42, F47

* Marcela Meirelles Aurelio is an economist at the Federal Reserve Bank of Kansas City. This research has benefited from discussions with Sebastian Edwards, Rossen Valkanov, Greg Hess, Todd Clark, Sharon Kozicki, Michael Orlando, Pu Shen and participants of FRB of Kansas City Research Seminar and of the Spring Meeting of the Federal Reserve System Committee on International Economic Analysis. I would like to thank, in particular, Luis-Felipe Zanna for his comments on an earlier draft, as well as Thomas Schwartz and Eli Wiseman for research assistance. The views expressed herein are solely those of the author and do not necessarily reflect the views of the Federal Reserve Bank of Kansas City or the Federal Reserve System.

Meirelles Aurelio email: marcela.meirelles.aurelio@kc.frb.org 


\section{Introduction}

Transparency has become one of the main attributes that characterize best-practice monetary policy and one of the advantages associated to inflation targeting (IT) regimes. ${ }^{1}$

Transparency can be understood as a property of the communication strategy of the Monetary Authority and in particular, of its policy statements. More generally, it can be a characteristic of the policy framework, both in terms of its objectives and of the factors driving current policy decisions.

Advocates of IT argue that this framework enhances transparency in all these dimensions. This happens because of the existence of an explicit target for inflation, which makes clear the goal of monetary policy, and also provides a benchmark that can be used to monitor policy outcomes. As a consequence, inflation expectations are anchored around the target, which results in the output cost of disinflation efforts being potentially smaller, compared to those observed in economies where monetary policy is conducted based on an implicit commitment to price stability.

Critics of this view argue, in contrast, that the existence of an explicit goal for the level of inflation does not necessarily increase the transparency of policy objectives or of the short term determinants of monetary policy actions. This skepticism is supported by the fact that policymakers have objectives other than that of keeping inflation close to the target, for instance, they also seek the stability of output around its potential level. Friedman (2004) argues that the omission of an explicit target for output growth results in a partial - and perhaps misleading - characterization of policy objectives. $^{2}$ In summary, the presence of an explicit inflation target may not be very informative about how policymakers will exercise their "constrained discretion" (Bernanke and Mishkin (1997)).

The proof of the pudding is in the eating, so it is potentially insightful to turn to the data and investigate whether it supports the view that monetary policy in IT regimes is transparent, despite the presence of other (less explicit) objectives. This analysis is conducted for the case of six countries that adopted IT in the early nineties: Australia, Canada, Chile, New Zealand, Sweden and United Kingdom.

\footnotetext{
${ }^{1}$ A definition of best-practice monetary policy and a thorough discussion of whether inflation targeting fits this definition can be found in Faust and Henderson (2004).

${ }^{2}$ Mishkin (2004) presents an opposing view.
} 
The dimension of monetary policy transparency which will be the focus of this research is the short-run predictability of policy actions. More specifically, the objective is to investigate the presence of a systematic behavior of the Monetary Authority, supported by the data, consistent with the goal of keeping inflation close (on average) to the target. In other words, the existence of other (potentially conflicting) objectives - such as the stability of output - should not prevent the record of policy decisions from displaying a significant degree of regularity and from being, therefore, largely predictable. Most importantly, if this predictable behavior is, at the same time, consistent with the announced goal, then we will have found evidence that these policy actions are, indeed, transparent.

The underlying assumption of this approach is that policy can be reasonably approximated by some kind of reaction function or interest rate rule. It is important, nevertheless, to be aware that this interpretation has limitations, as described by Poole (2003:5): "The fundamental problem is that there is no policy rule by which we can calculate the appropriate policy action from observed data. There is instead a regularity to policy of the sort "you know when you see it".

If that is the case, however, then it can be argued that the presence of an explicit target for inflation reinforces the regularity of policy actions, increasing the chances of the main determinants of monetary policy decisions being captured by a simple rule linking the interest rate to a limited set of variables. In addition, the presence of a (time-varying) explicit target for inflation, the availability of real time Central Bank's forecasts and of corresponding statements highlighting the importance of forward-looking behavior, all these are elements that provide additional structure to justify using reaction functions as a modelling strategy.

In fact, this approach has been followed in country-specific studies that investigated, empirically, the ability of simple interest rate rules to explain policy actions. ${ }^{3}$ In light of the findings of the existing literature, the contribution of the present paper is twofold.

First, it provides a comprehensive empirical assessment of the factors driving the instrument of monetary policy in the group of countries that have a longer history with IT, and this is done by using a methodology that is based on very general assumptions regarding the process driving this instrument. It is assumed that Central Bank's expected inflation and output/unemployment

\footnotetext{
${ }^{3}$ For example, Freitas et al. (2003), Berg et al (2004), Céspedes and Soto (2004), among others.
} 
gap summarize all the relevant information necessary to describe the systematic pattern of policy decisions. The choice of not using additional elements - such as the possibility that the Monetary Authority reacts to exchange rate fluctuations - is deliberate and reflects the desire to reach conclusions based on a minimum set of assumptions regarding policy determinants in the context of IT. It will be discussed later that this approach is still consistent with the assessment of policy decisions that are conducted in a "data-rich environment" (Bernanke and Boivin, 2003). In other words, it does not necessarily impose restrictive assumptions about the information-set used by policymakers.

Second, this paper contributes to this empirical literature by examining a wide range of possibilities in terms of the type of data used in estimation, as well as alternative assumptions regarding the time series properties of policy shocks, an issue that raises important implications to the required estimation strategy. The author is not aware of any other study of policy decisions in the context of inflation targeting that has provided a comprehensive analysis that encompasses multiple alternatives in terms of data selection and estimation procedures, in a relatively large sample of countries.

The methodology consists in estimating forward-looking interest rate rules. Estimation is performed using data up to the fourth quarter of 2000 , and then an out-of-sample forecasting exercise is performed. This is a important part of the empirical analysis conducted in the paper, since it can shed light on whether transparency of policy actions can be further supported by evidence of "ex ante predictability", or the degree to which the record of past policy decisions is indeed a useful guide that can be used to anticipate future policy actions, at least in the short run.

The same type of analysis is conducted for the case of the United States. Given the relatively short samples available for this econometric investigation, the comparison with the United States is not intended to provide a final answer about whether policy actions in the group of inflation targeters are more predictable than those in the United States. This limitation notwithstanding, the United States provides a useful benchmark of monetary policy actions that display a certain regularity, which, especially in the last decade, was likely a result of a strong (though implicit) commitment to price stability.

The paper is organized as follows. In the next section, policy reaction functions typically found in the literature and estimation issues are discussed. The second and third sections deal with the 
estimation methodology and results. Next, results from out-of-sample forecasts are discussed. The last section concludes. In the appendix, the small open economy model that motivates the moment conditions used in the estimation is described. Further details about the data set used in estimation are also provided in the appendix.

\section{Empirical Analysis of Policy Actions in IT Regimes: Limitations and Possible Approaches}

\subsection{Modeling IT using policy rules: a good idea?}

There is a main caveat associated to using results from empirical monetary rules in order to evaluate monetary policy under inflation targeting. The problem stems from the fact that if simple rules are just a reasonable approximation to the way policy is conducted in practice, then it is not surprising that they might fail to be a trustworthy guide to interpret policymakers decisions, especially those made during turning points of the business cycle.

The limitations of policy rules become even more evident when one takes into account policymakers statements that inflation targeting should be regarded as a broad framework for monetary policy, as opposed to a rule that is mechanically implemented by the Monetary Authority. Along this line, Svensson (2005) emphasizes the idea that policy actions result, to a great extent, from policymakers "judgement" about the current and future state of the economy, in a way that is not captured by the predictions of formal models and their corresponding policy reaction functions.

This limitation notwithstanding, there are several reasons to believe that using monetary policy rules as a benchmark to interpret monetary policy under IT can still lead to interesting insights. One is that the assumption that policymakers follow monetary policy rules - in particular Taylortype rules - is pervasive in theoretical research that investigates macroeconomic dynamics and the characteristics of optimal policy under inflation targeting. ${ }^{4}$

\footnotetext{
${ }^{4}$ A non exhaustive list includes Rudebusch and Svensson (1999); Hendry, Ho and Moran (2003) and Ambler, Dib and Rebei (2004) use this approach to analyse monetary policy under IT in Canada; Ryan and Thompson (2000) and Debelle and Wilkinson (2002) study inflation targeting in Australia; Céspedes and Soto (2005) investigate policy
} 
The second and most important justification, for the present purposes, is that the communication strategy of Central Banks typically involves statements linking policy decisions to a limited set of indicators, as if there was an implicit mapping relating these indicators to the instrument of monetary policy. In fact, research conducted by Central Bank's staff usually concludes that simple interest rate rules are a reasonable approximation to the underlying mechanism through which the short term policy interest rate is determined. ${ }^{5}$

\subsection{Policy Rules: General Features and Estimation Issues}

Batini and Haldane (1999) and Batini and Nelson (2001) suggest that targeting inflation can be thought in terms of setting the interest rate in response to deviations of future inflation from the target. This idea is captured by the forward-looking rule (where $E_{t}$ denotes expectations formed at time t):

$$
i_{t}^{*}=\text { constant }+\alpha_{\pi}\left(E_{t} \pi_{t+k}-\pi^{*}\right)
$$

where $i_{t}^{*}$ is the nominal short term interest rate (the "policy rate"), $\pi^{*}$ is a benchmark "desirable" level of inflation and $E_{t} \pi_{t+k}$ is expected inflation k periods ahead.

An alternative specification would include a term related to expected future deviations with respect to the output gap. For instance, a forward looking version of the Taylor rule is:

$$
i_{t}^{*}=\bar{r}+E_{t} \pi_{t+k}+\alpha_{\pi} E_{t}\left(\pi_{t+k}-\pi^{*}\right)+\alpha_{y} E_{t} y_{t+h}
$$

where $\bar{r}$ is the equilibrium real interest rate and $E_{t} y_{t+h}$ is the expected output gap h periods ahead.

Equation (2) can be modified to incorporate the existence of policy inertia. Let the actual process driving the policy rate $i_{t}$ be:

$$
i_{t}=\rho i_{t-1}+(1-\rho) i_{t}^{*}
$$

credibility under inflation targeting in Chile, and finally Lindé, Nessén and Söderström (2004) develop a structural open economy model to analyze inflation targeting in Sweden.

${ }^{5}$ See, for example, Berg, Jansson and Vredin (2004). 
Combining (2) and (3):

$$
i_{t}=\rho i_{t-1}+(1-\rho)\left[\bar{r}+E_{t} \pi_{t+k}+\alpha_{\pi} E_{t}\left(\pi_{t+k}-\pi^{*}\right)+\alpha_{y} E_{t} y_{t+h}\right]
$$

As discussed by Levin, Wieland and Williams (2003), equation (4) nests several of the policy reaction functions typically found in the literature. For example, (4) reduces to (2) with $\rho=0$. This policy reaction function is proposed by de Brouwer and Ellis (1998), as a good characterization of the forward looking monetary policy implemented in Australia under inflation targeting. Orphanides (2001) also allows for the presence of policy inertia and suggests the rule:

$$
i_{t}=\rho i_{t-1}+(1-\rho)\left[\alpha+\alpha_{\pi}^{*} E_{t} \pi_{t+k}+\alpha_{y} E_{t} y_{t+h}\right]
$$

where $\alpha=\bar{r}-\alpha_{\pi} \pi^{*}$ and $\alpha_{\pi}^{*}=1+\alpha_{\pi}$.

Clarida, Gali and Gertler (1998) propose a policy reaction function that closely resembles (4), with three important differences. In the equation that specifies the desired level of the policy rate, the term $\left(\bar{r}+E_{t} \pi_{t+k}\right)$ is replaced by a constant $\bar{i}$ that should capture the equilibrium nominal interest rate. Moreover, it is assumed that the forward-looking component refers only to inflation:

$$
i_{t}^{*}=\bar{i}+\alpha_{\pi} E_{t}\left(\pi_{t+k}-\pi^{*}\right)+\alpha_{y} y_{t}
$$

The third aspect in which the policy rule introduced by Clarida, Gali and Gertler (1998) differs from (4) is the presence of an exogenous disturbance or policy shock $v_{t}$. Allowing for the presence of inertia:

$$
i_{t}=\rho i_{t-1}+(1-\rho) i_{t}^{*}+v_{t}
$$

where $v_{t}$ is an exogenous monetary policy shock, possibly correlated over time ${ }^{6}$. Combining (6) and

\footnotetext{
${ }^{6}$ Clarida, Gali and Gertler (1998) impose the restriction that this shock is not serially correlated.
} 
(7), then (4) becomes:

$$
i_{t}=\rho i_{t-1}+(1-\rho)\left[\alpha+\alpha_{\pi} E_{t} \pi_{t+k}+\alpha_{y} y_{t}\right]+v_{t},
$$

where $\alpha=\bar{i}-\alpha_{\pi} \pi^{*}$.

Notice that it is straightforward to allow for a time varying inflation target, which is actually a feature of the data, especially during the early stages of the IT regimes. In this case, (8) becomes:

$$
i_{t}=\rho i_{t-1}+(1-\rho)\left[\alpha+\alpha_{\pi} E_{t}\left(\pi_{t+k}-\pi_{t+k}^{*}\right)+\alpha_{y} y_{t}\right]+v_{t},
$$

where $\alpha=\bar{i}$.

The question, then, is how to estimate (5) or (9). Clarida, Gali and Gertler (1998) suggest replacing the forward looking term by its observed value. The hypothesis underlying this procedure is that Central Bank's forecasts are efficient, and therefore forecast errors are unpredictable. In this case, the real time forecasts can be replaced by the actual realizations of the deviation of inflation from the target and (9) can be rewritten as:

$$
i_{t}=\rho i_{t-1}+(1-\rho)\left[\alpha+\alpha_{\pi}\left(\pi_{t+k}-\pi_{t+k}^{*}\right)+\alpha_{y} y_{t}\right]+\zeta_{t},
$$

where

$$
\begin{gathered}
\pi_{t+k}-\pi_{t+k}^{*}=E_{t}\left(\pi_{t+k}-\pi_{t+k}^{*} \mid \Omega_{t}\right)+\epsilon_{\pi, t+k}, \\
\zeta_{t}=-(1-\rho) \alpha_{\pi} \epsilon_{\pi, t+k}+v_{t},
\end{gathered}
$$

and $\epsilon_{\pi, t}$ is an unpredictable forecast error, such that, given information $\Omega_{t}$ available in time t:

$$
E_{t}\left(\epsilon_{\pi, t+k} \mid \Omega_{t}\right)=0
$$

The term $\zeta_{t}$ in (10) is a composite error term, given by the weighted sum of the forecast error and the policy shock. 
An alternative approach is to use real time Central Bank's forecasts to replace the forward looking terms. Leitemo (2005) argues that inflation targeting can be modelled in terms of a policy rule according to which the interest rate responds to the unchanged interest rate forecast of inflation. The Central Bank forecasts inflation, conditional on the maintenance of the interest rate at the current level (determined in the previous period), throughout the forecast horizon. Then, given this forecast, a new level for the interest rate is chosen, consistent with the objective of reducing deviations of the inflation forecast from the target. This "unchanged-interest-rate inflation forecast-based rule" is:

$$
i_{t}=\rho i_{t-1}+(1-\rho)\left[E_{t} \pi\left(\bar{i}_{t-1}\right)_{t+k}-\pi^{*}\right]
$$

where $E_{t} \pi\left(\bar{i}_{t-1}\right)_{t+k}$ is the four-quarter CPI inflation forecast (k periods ahead) contingent on the interest rate remaining unchanged over the forecast horizon.

Using this terminology, the forward looking rule proposed by Clarida, Gali and Gertler (1998) can be written as:

$$
i_{t}=\rho i_{t-1}+(1-\rho)\left[\alpha+\alpha_{\pi}\left(E_{t} \pi\left(\bar{i}_{t-1}\right)_{t+k}-\pi_{t+k}^{*}\right)+\alpha_{y} y_{t}\right]+v_{t},
$$

More generally, assuming that the term corresponding to real economic activity is also forward looking, the rule becomes:

$$
i_{t}=\rho i_{t-1}+(1-\rho)\left[\alpha+\alpha_{\pi}\left(E_{t} \pi\left(\bar{i}_{t-1}\right)_{t+k}-\pi_{t+k}^{*}\right)+\alpha_{y} E_{t} y\left(\bar{i}_{t-1}\right)_{t+k}\right]+v_{t}
$$

The approach of using real-time forecasts is followed by Kuttner (2004), for the case of New Zealand, Sweden, and United Kingdom and United States, and by Orphanides (2001), who estimates (5) for the US. ${ }^{7}$ Unfortunately, most central banks have not, until recently, published their forecasts on a systematic basis. The Central Banks of New Zealand, Sweden and United Kingdom are an exception, having started to publish forecasts relatively in the early stages of IT.

\footnotetext{
${ }^{7}$ Kuttner (2004) was a pioneer in the use of Central Bank's real time forecasts to estimate reaction functions in a group of countries that target inflation. A subset of the data/estimation procedures performed in this paper is similar to those employed in his paper. Empirical results differ somewhat, probably because of differences in the sample range and equation specifications.
} 
Of the list of countries with a sufficiently long record of published forecasts, Sweden and United Kingdom are the only ones to provide constant-interest-rate forecasts. ${ }^{8}$

From the point of view of the empirical assessment of policy determinants, however, the availability of constant-interest-rate forecasts is very attractive. The reason is that, under certain assumptions, these forecasts can be considered predetermined variables in period $t$, and consistent parameter estimates can be computed running ordinary least squares (OLS) regression. ${ }^{9}$ The possibility of conducting a simple OLS estimation in this context, in turn, is very convenient, because the actual forecast can be used as a regressor, instead of a proxy for it (in the case when the potential endogeneity of the forecast requires the use of instruments for estimation).

In the absence of real time forecasts, equation (10) can be estimated by instrumental variables and, more generally, using generalized method of moments (GMM) techniques. A potential drawback is that empirical research has found that residuals from estimated policy rules tend to be significantly correlated over time, even after allowing for the presence of policy inertia. ${ }^{10}$ The presence of shocks that are correlated over time imposes severe constraints on estimation, because lagged endogenous variables - which are potentially good instruments - are no longer orthogonal to the composite disturbance $\zeta_{t}$ and hence, strictly speaking, cannot be used as instruments.

This situation generates a trade-off when it comes to choosing instruments. On one hand, good instruments - from the point of view that they are correlated with the potentially endogenous regressors - no longer generate valid moment conditions. On the other hand, when exogenous but "weak instruments" are available - weak in the sense that they are not sufficiently correlated with the regressors, and the model is, in essence, unidentified - then estimators based on GMM procedures are not precise and there is evidence of bias in the t-statistics. ${ }^{11}$

One way to circumvent these limitations, which is explored in this paper, is to conduct a wider search for instruments, in particular, to explore the information content of variables in the international goods and capital markets, whenever GMM estimation is required. ${ }^{12}$ Details of this estimation

\footnotetext{
${ }^{8}$ Recently, the Central Bank of Sweden (Riksbank) announced a change in the methodology used to generate forecasts, which will be exclusively based on time-varying interest rates consistent with market projections.

${ }^{9}$ The required assumption is that the policy shock $\nu_{t}$ is uncorrelated over time.

${ }^{10}$ See, for instance, Rudebusch (1999).

${ }^{11}$ For a complete discussion of these issues, please refer to Stock, Wright and Yogo (2002).

${ }^{12}$ In fact, it seems to be the case that the problem of weak instruments is not present here, in the case of models
} 
strategy will be discussed in the next section.

\section{Estimation Procedure}

\subsection{Methodology}

Different versions of a forward-looking interest rate rule are estimated. These different alternatives are investigated in order to incorporate the availability of real-time Central Bank's forecasts for some of the countries in the sample. It also reflects the objective of conducting estimation under different assumptions concerning the time series properties of the residuals or "policy shocks".

Model I and II use observed future values of the deviation of inflation from the target. Model I is specified as:

$$
i_{t}=\rho i_{t-1}+(1-\rho)\left(\alpha+\alpha_{\pi}\left(\pi_{t+k}-\pi_{t+k}^{*}\right)+\alpha_{y} y_{t}\right)+\zeta_{t}
$$

where $\zeta_{t}$ is possibly serially correlated over time. If that is the case, then lagged values of the interest rate and of the regressors are unlikely to be orthogonal to the disturbance $\zeta_{t}$.

GMM estimation is implemented, using a set of instruments, collected in a vector that will be denoted by $Z$. In essence, the vector $Z$ contains worldwide indicators of economic activity, productivity and liquidity in international markets.

The rationale behind using these instruments is described in the appendix. The underlying assumption is that these worldwide indicators of liquidity and economic activity are correlated with the endogenous regressors (inflation and the output gap), but they are not omitted variables that should have been included in the policy rule. In other words, they matter only insofar policymakers use (efficiently) their information content to update their beliefs about the domestic economic outlook.

estimated using GMM, and foreign variables as instruments. A simple OLS regression of the potentially endogenous regressors (inflation deviation from the target and unemployment gap) on these foreign variables generates quite high $R^{2}$. In a multivariate linear context, Shea (1997) warns against this kind of procedure to assess the quality of the instruments. The problem is that if the potentially endogenous regressors are highly correlated, then high $R^{2}$ of separate regressions on the instruments is not going to be very informative (in essence, the model can still be unidentified). The importance of this warning notwithstanding, the correlation between the (future) deviation of inflation from the target and the unemployment gap, in the data set employed in this paper, is not very high (in some cases being quite small, actually). Therefore, the results of individual OLS regressions on the instruments are, potentially, more informative. 
If these assumptions hold, then variables in the vector $Z$ will be uncorrelated with the composite disturbance (the weighted sum of the forecast error and the policy shock). The corresponding moment condition is:

$$
E_{t}\left(\zeta_{t} Z_{t-j}\right)=0 \quad \text { for } j=1,2, \ldots
$$

Model II is the same as model I, but now the restriction that shocks are serially uncorrelated is imposed:

$$
i_{t}=\rho i_{t-1}+(1-\rho)\left(\alpha+\alpha_{\pi}\left(\pi_{t+k}-\pi_{t+k}^{*}\right)+\alpha_{y} y_{t}\right)+\zeta_{t}, \quad \zeta \sim i i d \quad N\left(0 ; \sigma_{\zeta}^{2}\right)
$$

Model II is also estimated using GMM, with the moment conditions based on the orthogonality of lagged values of the right hand side variables, which, in turn, is a consequence of the assumption that $\zeta$ is iid. Estimation of models I and II is conducted using a heteroskedasticity and autocorrelation (HAC) consistent estimator of the matrix of variance and covariance of moments. ${ }^{13}$ Andrews and Monahan (1992) prewhitening technique was used.

It should noted that even though the moment conditions used in estimation are motivated by a simple small open economy model (described in the appendix), a limited information procedure is implemented, in the sense that estimation is restricted to the equation that describes the policy reaction function, as opposed to estimation of the complete set of equations that would describe the economic environment. ${ }^{14}$ This choice reflects the objective of having an agnostic view about the underlying macroeconomic environment, given that the economies in the sample differ considerably from each other. For the same reason, estimation refers to instrument rules as opposed to inflation forecast targeting rules, which by definition are model dependent. ${ }^{15}$ Note that this "limited information" approach is consistent with exploring the richness of information in the data. In fact, the estimation procedure proposed here partially addresses the criticism that simple interest rate rules

\footnotetext{
${ }^{13}$ For a discussion of nonlinear GMM estimation procedures and, in particular, of the estimation of the moments covariance matrix, please refer to Greene (2000) and Mátyás (1999).

${ }^{14}$ An example of full information approach is given by Lubik and Schorfheide (2003).

${ }^{15}$ For a discussion of instrument versus inflation forecast targeting rules, see McCallum and Nelson (2004).
} 
implicitly assume that policymakers look at a restricted set of variables, whereas in practice a much richer set of indicators influence policy decisions. ${ }^{16}$

Models III and IV are used when real-time Central Bank's forecasts are available. Model III is specified as:

$$
i_{t}=\rho i_{t-1}+(1-\rho)\left[\alpha+\alpha_{\pi}\left(E_{t} \pi(\widetilde{i})_{t+k}-\pi_{t+k}^{*}\right)+\alpha_{y} y_{t}\right]+v_{t}, \quad \nu \sim i i d N\left(0 ; \sigma_{\nu}^{2}\right)
$$

where $E_{t} \pi(\widetilde{i})_{t+k}=E_{t} \pi\left(\bar{i}_{t-1}\right)_{t+k}$ as in (15), for the case of forecasts based on a flat path of the policy interest rate, during the forecast horizon k. Alternatively, $E_{t} \pi(\widetilde{i})_{t+k}$ indicates forecasts of the inflation rate, conditional on a certain time-varying path of the interest rate.

Model IV assumes that both inflation and output gap terms are forward looking. As in model III, real time Central Bank's forecasts are used:

$$
i_{t}=\rho i_{t-1}+(1-\rho)\left[\alpha+\alpha_{\pi}\left(E_{t} \pi(\widetilde{i})_{t+k}-\pi_{t+k}^{*}\right)+\alpha_{y} E_{t} y(\widetilde{i})_{t+k}\right]+v_{t}, \quad \nu \sim i i d N\left(0 ; \sigma_{\nu}^{2}\right)
$$

Parameters in equations (20) and (21) are estimated using (nonlinear) least squares. In the case of Central Banks whose forecasts are based on time varying path of interest rates, instrumental variables estimation is used.

To fix ideas, Table (1) summarizes the baseline models used in the empirical analysis.

\subsection{Data}

\subsubsection{Policy Interest Rates, Inflation and Inflation Targets}

Estimation is based on quarterly, seasonally adjusted data (if applicable). The policy interest rate used in the estimations corresponds to the quarterly average of the (end of month) short term interest

\footnotetext{
${ }^{16}$ To see why, it suffices to notice that GMM parameter estimates corresponding to the moment conditions (18) become close to those obtained with a simple two-stage least squares (TSLS) estimation, when residuals are (close to) being serially uncorrelated and homoskedastic. In turn, a simple TSLS procedure would amount to replacing the observed endogenous regressor by linear predictions based on the instruments. In this sense, the methodology shares features of the approach used by Bernanke and Boivin (2003), who suggested exploring the fact that policy decisions are carried on in a "data rich environment", which can be used to compute these predictions.
} 
rate that is used as the instrument of monetary policy. Inflation is measured by the percentage change in the consumer price index (CPI) within a quarter, at an annual rate. ${ }^{17}$ The measure of inflation used in the estimation is the four-quarters average of this quarterly indicator, computed over the last four quarters, including the current one.

The official target for inflation is usually announced in terms of the headline consumer price index $(\mathrm{CPI})^{18}$, but Central Banks typically monitor other CPI indexes, in particular those that exclude food, energy and mortgage costs. The procedure followed in this paper was to report results of regressions using the headline CPI index unless the fit of regressions unequivocally suggested that core inflation measures should be employed. This was the case of Australia, in which case the CPI excluding most volatile items (fruits, vegetables, property rates and charges, health services, etc.) was used. A similar procedure was followed for Canada. The indicator used was the Canadian Central Bank's measure of core inflation, which is explicitly defined as the operational target.

By the time inflation targeting was adopted, an inflation goal corresponding to the 4 quarters change in the consumer price index was announced. Most central banks decided that the target should be met by the end of the current or of the following calendar year, and then announced different (usually lower) targets, to be achieved by the end of the subsequent years.

Based on this information, a monthly target series was constructed, assuming a constant disinflation rate throughout the convergence period and imposing the restriction that, on the last month of the convergence period, the target was exactly equal to the desired end-of-period level announced by the Monetary Authority. Quarterly rates were then constructed as an average of these monthly figures. ${ }^{19}$

Once inflation became close to the desired long term target (at a level consistent with the Central Bank's definition of price stability), then a constant inflation target, valid thereafter, was announced. This shift to a constant, multi-period target level was accompanied by a change in the way Central

\footnotetext{
${ }^{17}$ Policy statements in inflation targeting regimes usually refer to 4 quarters accumulated inflation. In this empirical analysis, the inflation rate within a quarter at an annual rate is used instead. The justification is to have a measure of inflation that is a good proxy for the indicator used in practice by policymakers, especially in the presence of forward looking behavior.

${ }^{18}$ The exception in the sample is the United Kingdom, whose official target was the RPIX, a measure of the CPI index that excludes mortgage interest payments, until it was substituted by the headline CPI, in 2004.

${ }^{19}$ One exception is New Zealand, given that a time varying, quarterly series for the inflation target is available from the Central Bank website.
} 
Banks communicated their goals to the public: instead of the target referring to annual inflation measured by the end of the calendar year, it was associated to the average inflation, measured by the 12 months change of the CPI index. This provides justification for using an average measure of inflation in the specification of the forward looking rules to be estimated.

\subsubsection{Index of Economic Activity}

The empirical literature on policy reaction functions has used a variety of indices of economic activity and of methods to detrend them. These indicators can be direct measures of the output gap, as well as detrended measures of output, unemployment rates or industrial production indexes.

In the present study, the (Hodrick-Prescott filtered) quarterly average, seasonally adjusted, unemployment rate is used as the index of economic activity $y_{t}$, whose current value appears in the hypothetical policy reaction functions here examined. The only exception will be the case of the United States, in which case a real-time measure of the unemployment gap was used. ${ }^{20}$

The choice of the detrended unemployment rate has two appealing attributes: first, it is closely monitored by policymakers and second, it is available monthly and without much delays, so it is reasonable to assume that its information content is readily incorporated in policy decisions.

\section{Parameter Estimates}

\subsection{General Findings}

As discussed in the introduction, inflation targeting regimes do, in practice, encompass multiple policy objectives - in particular, the (implicit) goal of keeping output close to potential and the (explicit) goal of keeping inflation close to the target. Does this multiplicity of policy objectives lead to policy actions such that market participants would not be able to have a clear-cut interpretation

\footnotetext{
${ }^{20}$ This measure of the unemployment gap was computed using real-time data on the NAIRU, from the dataset constructed by Kozicki (2004), together with the real-time data on the unemployment rate, available on the Federal Reserve Bank of Philadelphia website. For more information on US real-time data, see Croushore and Stark (2001).
} 
of the determinants of policy decisions? After all, does the data support the view that monetary policy under IT is systematic, predictable, consistent with the inflation target, and, in this sense, transparent?

To answer this question, the forward looking interest rate rules described in the previous section were estimated and the results are reported in Tables (2) and (3). Conclusions can be summarized as follows:

(1) The main finding is that, even though the record of policy actions displays a strong emphasis on stabilizing unemployment around its natural level, this feature does not prevent the data from revealing, at the same time, a clear systematic - and statistically significant - reaction to deviations from the target. Most importantly, this regularity in Monetary Authority actions is consistent with the attainment of the inflation target. In other words, the coefficient that captures the reaction to expected deviations of inflation from the target has the expected sign, showing unequivocally that monetary policy tends to be tightened when inflation is expected to rise above the target.

(2) There seems to be important implications associated to the use of future observed values to replace the forward looking terms (models I and II), compared to when real-time Central Bank's forecasts are used in the estimation (models III and IV). When real-time forecasts are used, parameter estimates are more precise and yield estimated coefficients for the reaction to inflation deviations from the target that are always statistically significant and have the expected sign.

(3) This conclusion is not surprising. In well-functioning inflation targeting regimes, ex post realized deviations of inflation from the target should be quite small and largely driven by unexpected shocks. Most importantly, they may differ substantially from the conditional forecasts that are taken into account by monetary policy committee members, when deciding the level of the policy interest rate. As an illustration of this point, in the case of Sweden, when real-time Central Bank's forecasts of inflation are used (models III and IV), the data reveals an unambiguous, statistically significant reaction to expected deviations of inflation from the target (with the right sign). This is not the case when ex post observed values are used. 
(4) This feature may also explain the estimated reaction to (observed) deviations from the target, in the case of Australia. The estimated reaction function has a good fit, revealing policy actions that are, in large part, predictable. They fail, nevertheless, to conform to our definition of transparency, because the parameter estimate is at odds with what one should expect, given the announced target: empirical estimates suggest that interest rates fail to react at all, in the event of an expected increase of inflation during the quarters ahead. This finding may be driven by the lack of real-time Central Bank's forecasts for the case of Australia, which could improve the quality of the regression.

(5) Finally, the attribute of transparency of policy decisions - the presence of regularity and short run predictability of policy actions, in a way consistent with price stability - is also present in the case of the United States during the nineties, despite the absence of an explicit target for inflation.

\subsection{Is There Evidence of International Monetary Policy "Contagion"?}

Large fluctuations of exchange rates can be triggered by changes in international interest rate differentials. Therefore, changes in the direction of monetary policy in large economies such as the US and the European Monetary Union can have an important impact on policy decisions in countries that target inflation. This is not inconsistent with inflation targeting, since the path of exchange rates carry important information concerning future inflation. However, if that is the case, then the forward looking terms of the empirical interest rate rules should suffice to capture the potential effect of foreign monetary policy. If not, then one might once again cast doubt on the transparency of policy actions under IT.

In order to examine this issue, an alternative version of Model I is estimated:

$$
i_{t}=\rho i_{t-1}+(1-\rho)\left(\alpha+\alpha_{\pi}\left(\pi_{t+k}-\pi_{t+k}^{*}\right)+\alpha_{y} y_{t}+\alpha_{i} \Delta i_{t-1}^{*}\right)+\zeta_{t},
$$

where $i^{*}=i^{U S}$, the US federal funds rate or $i^{*}=i^{E C B}$, the European Central Bank rate of main refinancing operations. The term $\Delta i_{t-1}^{*}$ indicates the change in these foreign policy interest rates, between time (t-1) and (t-2). 
Table (3) summarizes the parameter estimates. The inclusion of the lagged change of foreign interest rates does not change the conclusions discussed in the previous section. In most cases, the parameter capturing the effect of monetary policy decisions in the US and in the European Monetary Union is not significantly different than zero. These foreign interest rates probably do convey "news" that are taken into account by policymakers, but this effect is already captured by the forward looking inflation and unemployment gap terms of the interest rule.

Australia and Sweden are the exception, with the coefficient on lagged changes of the US federal funds rate being quite large and statistically significant. However, a quick inspection of graphs (1) and (5) shows that a model that does not incorporate the effect of the federal funds rate already does a good job predicting policy actions. This might suggest that the coefficient on the change of the federal funds rate might be in reality capturing another feature of the data. For instance, instead of revealing policy contagion, this coefficient might be capturing the presence of a time varying equilibrium interest rate.

The out-of-sample forecasting exercise described in the next section will shed additional light on this issue.

\section{Out of Sample Forecasts}

It is important to know if the empirical regularities previously discussed are robust and stable enough so that they can also be used as a guide to anticipate policy decisions. This is a crucial aspect, because one of the main advantages typically associated to transparent monetary policy regimes is that market participants can have a reasonable degree of confidence in their ability to predict policy actions, at least in the near future. This property, in turn, is key in the argument that transparent policy regimes are more successful in anchoring inflation expectations.

In order to investigate this feature of the data, models I through IV were estimated using data up to the fourth quarter of 2000 and then out-of-sample predictions were computed. ${ }^{21}$ Two forecasting

\footnotetext{
${ }^{21}$ Given the limited amount of forecast points, confidence intervals for these forecasts would not rule out the possibility that they could be identical to the observed value of the policy rate. For the same reason, one could not rigorously
} 
exercises are performed:

- One step ahead forecasts, which use the observed policy rate in (t-1) as one of the arguments to forecast the policy rate in time t. ${ }^{22}$

- Dynamic forecasts, that use the forecasted value of the policy rate in (t-1), to predict the policy rate in time t.

In both cases, the only variable being forecasted is the interest rate itself, in the sense that the right hand side variables are values actually observed. Models I through IV are used in this exercise. In addition, it would be interesting to know if we can do better with alternative models. Two alternatives are investigated. First, a simple Taylor rule of the form:

$$
i_{t}=\rho i_{t-1}+(1-\rho)\left[\alpha+\alpha_{\pi}\left(\pi_{t}-\pi^{*}\right)+\alpha_{y} y_{t}\right]+\varepsilon_{t}, \quad \varepsilon \sim i i d \quad N\left(0 ; \sigma_{\varepsilon}^{2}\right)
$$

Second, an $\mathrm{AR}(1)$ process:

$$
i_{t}=\mu+\rho_{1} i_{t-1}+\epsilon_{a r, t}, \quad \epsilon_{a r} \sim i i d \quad N\left(0 ; \sigma_{\epsilon_{a r}}^{2}\right)
$$

which can shed light on the actual amount of information that deviations of inflation from the target and the unemployment gap add to the interpretation of the process driving interest rates.

The results of this exercise are described in Tables (5) and (6), which contain the root mean squared error (RMSE) of forecasts for different forecast horizons and models.

To further illustrate the characteristics of these forecasts, graphs (1) through (7) show a plot of the observed policy rate, and of one-step-ahead and dynamic predictions of model I (for those countries where a sufficiently long series of real-time Central bank's forecasts is not available), and of model III or IV otherwise. The vertical bar indicates the beginning of out of sample forecasts.

A few aspects are worth being highlighted:

(1) Graphs (1) through (7) show that, with the exception of Australia and Sweden, the out-ofrank these models based on differences in the size of root mean squared errors. An additional source of difficulty is given by the fact that an exact expression for the variance of the forecast errors, given the type of models that were estimated, is not available.

${ }^{22}$ Notice that these out-of sample forecasts are not computed using rolling regressions, i.e. an additional data point is not incorporated to the sample as we move along in time. 
sample forecasts tend to overpredict the policy interest rate, in the group of inflation targeters, as well as in the United States. However, they still render support to the view that policy actions are predictable, in the sense that they show that it is possible to anticipate policy actions with a reasonable degree of accuracy. Probably because of the time-varying equilibrium interest rate, a feature that is not captured by models I - IV, these forecasts fail to reproduce the level of the actual rate, but they predict quite well the direction of policy.

(2) While policy actions in Australia and Sweden are remarkably predictable, both in and out-ofsample, the same is not true from New Zealand and Chile. In the case of these economies, a simple AR(1) model outperforms the more elaborate forward looking models, in terms of their root mean squared errors. Inspection of the plots of actual and predicted values suggest that, especially in the case of New Zealand, a clearer mapping between policy decisions and inflation/unemployment gap might be blurred, from an empirical point of view, by the effect of episodes such as the 1997/98 Asian crisis.

(3) The results of this out-of-sample forecasting exercise confirm that policy actions in inflation targeting regimes are, in general, predictable. However, in some cases predictability is accompanied by features of the data that are at odds with what one might expect a priori. Perhaps the most remarkable example is given by Australia. The estimated parameter that captures the reaction to deviations of inflation from the target is close to zero and statistically insignificant. Despite this feature, even the dynamic forecasts of model I display a very good fit, both in and out-of-sample. This is also the model whose out-of-sample forecasts display the smallest root mean squared error. 


\section{Conclusions}

Transparent monetary policy frameworks yield policy actions that are predictable, at least in the short run, because the process driving the interest rate displays a regularity that is consistent with the announced policy objectives. Departing from this definition of transparency, this paper investigated empirically whether inflation targeting regimes possess this desirable property, both "in sample and out of sample".

The investigation was motivated by the fact that policymakers have other less explicit - and possibly conflicting goals - other than the attainment of the inflation target. Policy decisions also reflect the objective of reducing fluctuations of output around its potential level, of providing a stable environment for financial markets and, perhaps, that of adjusting to changes in monetary policy in foreign economies, in order to attenuate fluctuations of nominal exchange rates.

In the presence of these multiple explicit and implicit goals, can we still say that policy decisions in inflation targeting regimes are transparent? The answer to this question is qualified 'yes', based on the empirical findings for the group of six inflation targeters analyzed in this paper.

Not only the record of policy actions displays a substantial degree of regularity, but also this systematic reaction of the Monetary Authority to certain key economic variables is consistent with the goal of keeping (on average) the inflation rate close to the target. The empirical analysis presents robust evidence that monetary policy tends to be tightened when inflation is expected to rise above the target. This evidence is particularly solid when real-time central bank's forecasts are available. This is the case of Sweden, whose record of policy actions is, according to our definition, very transparent, both "in and out of the sample".

Most importantly, it is also straightforward to conclude that policymakers are not "inflation nutters" 23 The data also reveals an unambiguous role played by information regarding the unemployment gap. Some goals are not explicit as the inflation target is, but this does not prevent the record of policy decisions from providing a clear-cut message concerning the overall objectives of the Monetary Authority in IT regimes.

\footnotetext{
${ }^{23}$ Terminology introduced by King (1997).
} 
There are a few aspects of the empirical findings that suggest, nevertheless, that these results should be interpreted with caution.

If transparency is interpreted in a broader sense, such that it also encompasses the way the Monetary Authority communicates its objectives, then the result that output/unemployment gap terms matter a lot for policy decisions may cast doubt on the actual degree of transparency of IT regimes. As some authors pointed out (Friedman (2004), Faust and Henderson (2004)), why not talk about the output stabilization goal more explicitly?

Another issue is that the empirical findings, although robust across different economies, also unveil a certain degree of heterogeneity and country specific "puzzles". For instance, Sweden provides a textbook example of IT regime in which policy actions are very transparent, in the sense that the time series behavior of the interest rate is quite predictable, and at the same time, the parameter estimates of the empirical reaction function are consistent with what one might expect a priori. However, policy decisions in Australia are even more predictable, both in and out-of-sample, using a simple forward looking reaction function. Nevertheless, the corresponding parameter that captures the reaction to inflation deviations from the target is very small and not significantly different than zero.

This result might be capturing the fact that the future inflation deviation from the target (used in the estimation of the Reserve Bank of Australia interest rule) is hard to predict. This might be a consequence of the fact that, in well functioning IT regimes, foreseeable deviations should trigger changes of the policy rate such that, ex post, such deviations are not only smaller than otherwise they would have been, but also more random (in the sense that they are, by and large, a consequence of unanticipated shocks). In light of this, to use real-time Central Bank's conditional forecasts (conditional on a certain path of the interest rate, such as a flat path), might help resolve this issue. Unfortunately, only recently countries like Australia and Canada started publishing, regularly, a time series of numerical forecasts, which can be considered an important move towards a really transparent framework.

In some cases, significant and persistent differences between the predicted and the observed policy interest rate do occur. This is the case of Chile and New Zealand, in particular during periods of 
turmoil in international capital markets. These deviations are large and persistent enough to blur our understanding about the practical importance of the inflation and unemployment gap terms in the reaction function. Accordingly, a simple AR(1) model does a better job fitting the data out of the sample.

Another feature that suggests caution in the interpretation of the results is the fact that, in some cases, out of sample forecasts can be improved, if one conditions domestic policy decisions on changes of the US federal funds rate. This is the case of Canada, and especially of the United Kingdom. Interestingly, in neither of these cases the parameter capturing the effect of the lagged change in the federal funds rate is significantly different than zero. This may suggest that the inclusion of this term might be capturing, in reality, a reduction in the perceived equilibrium nominal interest rate.

Finally, it should be highlighted that, according to the definitions proposed in this paper, monetary policy in the US economy, since early nineties, seems to be at least as predictable, consistent with price stability and transparent, as the inflation targeting regimes examined here. In this sense, the presence of an explicit target for inflation does not seem to be a necessary requirement for transparent policy actions, at least according to the interpretation of transparency that oriented this discussion. In fact, this result reinforces the view that the US does not currently suffer from a weak nominal anchor, which of course does not rule out the possibility that "the strong nominal anchor is embodied in Alan Greenspan".(Mishkin, 2004:119). Future events and further research will certainly shed more light on this issue.

\section{Appendix}

\subsection{A Stylized Small Open Economy Framework}

In this section, the economic environment that motivates the choice of foreign variables as instruments used in the GMM estimation of model I is discussed. The purpose of outlining this model is solely that of providing a framework that will discipline the choice of instruments for estimation, and that of making more explicit the required assumptions that generate valid moment conditions. 
The model describes a small open economy where two types of final goods are produced and classified as tradable and non-tradable. For simplicity, the tradable good is treated as an homogeneous commodity, that can also be purchased from abroad.

The consumption index is given by the following expression, where $C_{t}^{T}$ is the domestic consumption of tradables and $C_{t}^{H}$ :

$$
C_{t}=\left(C_{t}^{T}\right)^{\alpha}\left(C_{t}^{H}\right)^{1-\alpha}
$$

The domestic price of tradable and nontradable goods are $P_{t}^{T}$ and $P_{t}^{H}$, respectively, and the consumption price index is:

$$
P_{t}=\left(P_{t}^{T}\right)^{\alpha}\left(P_{t}^{H}\right)^{1-\alpha}
$$

Let $P_{t}^{T^{*}}$ be the exogenously given world price of the tradable good and $S_{t}$ the nominal exchange rate. Assume that the law of one price holds, so the domestic price of the tradable good $P_{t}^{T}$ is simply equal to $S_{t} P_{t}^{T^{*}}$. The real exchange rate can then be defined as:

$$
e_{t}=\frac{P_{t}^{T}}{P_{t}^{H}}=\frac{S_{t} P_{t}^{T^{*}}}{P_{t}^{H}}
$$

The nominal exchange rate depreciation in period $\mathrm{t}$ is given by:

$$
\varepsilon_{t}=\frac{S_{t}}{S_{t-1}}
$$

Equation (26) can be used to express consumer price index (CPI) inflation $\pi_{t}$ :

$$
\pi_{t}=\alpha\left(\varepsilon_{t}+\pi_{t}^{T^{*}}\right)+(1-\alpha) \pi_{t}^{H}
$$

where $\pi_{t}^{T^{*}}$ is the inflation rate of the world price of tradable goods and $\pi_{t}^{H}$ is the inflation rate in the nontradable sector. To motivate the role of monetary policy - i.e. its ability to have real effects on the economy, in the short term - assume the presence of price rigidities in the nontradable good producing sector.

Suppose that each sector produces output using capital $K$ and labor $N$, according to a Cobb- 
Douglas production function. The output in the traded goods sector $\left(Y_{t}^{T}\right)$ and in the nontraded goods sector $\left(Y_{t}^{H}\right)$ is given by, respectively:

$$
\begin{gathered}
Y_{t}^{T}=A_{t}^{T}\left(K_{t}^{T}\right)^{\theta}\left(N_{t}^{T}\right)^{1-\theta}, \\
Y_{t}^{H}=A_{t}^{H}\left(K_{t}^{H}\right)^{\mu}\left(N_{t}^{H}\right)^{1-\mu},
\end{gathered}
$$

where $A^{T}$ and $A^{H}$ are exogenous productivity shocks.

Households buy tradable and nontradable goods, which can be either consumed $\left(C_{t}^{T}, C_{t}^{H}\right)$ or invested $\left(I_{t}^{T}, I_{t}^{H}\right)$. Part of the purchases of tradable goods may come from elsewhere in the world. The total amount of imports $F_{t}$ is given by the sum of imports used for consumption purposes $F_{t}^{C}$ and those units devoted to investment $F_{t}^{I}$. The total domestic tradable output is given by the following expression, where $X_{t}$ is the number of tradable good units that are exported to the rest of the world:

$$
Y_{t}^{T}=\left(C_{t}^{T}-F_{t}^{C}\right)+\left(I_{t}^{T}-F_{t}^{I}\right)+X_{t}
$$

Households hold an internationally traded bond, denominated in units of the tradable good. Assume, without loss of generality, that households are net debtors in the external market, so $D_{t}$ is the amount of net external liabilities that matures one period later, paying the gross interest rate $\left(1+i_{t}^{F}\right)$.

The economy's aggregate resource constraint, which defines the current account, $C A_{t}$ is given by:

$$
C A_{t}=D_{t}-D_{t-1}=N X_{t}+i_{t-1}^{F} D_{t-1}
$$

The interest rate charged on foreign loans to domestic residents is equal to the exogenous world nominal rate $i_{t}^{*}$, plus a country risk premium term $\xi$

$$
\left(1+i_{t}^{F}\right)=\left(1+i_{t}^{*}\right)\left(1+\xi_{t}\right),
$$


and the uncovered interest parity condition is:

$$
1+i_{t}=E_{t}\left(1+i_{t}^{F}\right)\left(1+\varepsilon_{t+1}\right)
$$

where $i_{t}$ is the domestic interest rate.

Monetary policy is characterized by a policy reaction function, where $y$ is the unemployment gap. The interest rate rule is:

$$
i_{t}=\rho i_{t-1}+(1-\rho)\left[\alpha+\alpha_{\pi} E_{t}\left(\pi_{t+k}-\pi_{t+k}^{*}\right)+\alpha_{y} y_{t}\right]+v_{t}
$$

where $v_{t}$ is a "policy shock". The time varying target is a policy variable which is announced several periods in advance, so that $\pi_{t+k}^{*}$ is a predetermined variable at time t.

Finally, let $Z_{t}^{*}$ be the vector of exogenous variables, given by the sector specific productivity shocks $A_{t}^{T, H}$, the international price of tradable goods $P_{t}^{*}$, the world interest rate $i_{t}^{*}$ and the country risk premium $\xi_{t}$ so $Z_{t}^{*}=\left[\begin{array}{llllll}A_{t}^{T} & A_{t}^{H} & P_{t}^{*} & i_{t}^{*} & \xi_{t} & v_{t}\end{array}\right]$. Assume that their time series behavior, in deviation from the mean, is given by:

$$
Z_{t}^{*}=\Phi Z_{t-1}^{*}+\Psi_{t}
$$

where $\Phi$ is a $(5 x 5)$ matrix of autoregressive coefficients and $\Psi_{t}$ is a $(5 x 1)$ vector of innovations, possibly correlated with each other, but uncorrelated over time. The only restriction that will be imposed is that the policy shock $v_{t}$ is uncorrelated with any of the other variables in the vector $Z_{t}^{*}$. This amounts to saying that $A_{t}^{T}, A_{t}^{H}, P_{t}^{*}, i_{t}^{*}$ and $\xi_{t}$ are not variables that should have been included in the policy rule (36). Formally, let $Z_{t}$ be this restricted vector that contains the exogenous variables, excluding $v_{t}$. The restriction is, with variables in deviation from their means:

$$
E_{t}\left(Z_{t-h} v_{t-i}\right)=0 \quad \text { for } \forall h=0,1,2, \ldots i=0,1,2, \ldots
$$

Given this description of the economic environment, forecasts can be constructed based on a 
reduced form, rational expectations solution of the model, which can be expressed as:

$$
\begin{aligned}
& Q_{t}=A Q_{t-1}+B Z_{t}^{*}, \\
& Y_{t}=C Q_{t-1}+D Z_{t}^{*},
\end{aligned}
$$

where $Q$ is a vector of endogenous predetermined variables, like the domestic capital stock and the inflation target, and $Y_{t}$ is a vector that contains the remaining endogenous variables, like CPI inflation, and $Z^{*}$ is the previously defined vector of exogenous variables. Using equations (37), (39) and (40) we have expressions for the value of each variable, $\mathrm{k}$ periods ahead:

$$
\begin{gathered}
Z_{t+k}^{*}=\Phi^{k+1} Z_{t-1}^{*}+\sum_{j=0}^{k} \Phi^{j} \Psi_{t+k-j} \\
Q_{t+k}=A^{k+1} Q_{t-1}+\sum_{j=0}^{k} A^{j} B\left(\Phi^{k+1-j} Z_{t-1}^{*}+\sum_{m=0}^{k-j} \Phi^{m} \Psi_{t+k-j-m}\right) \\
Y_{t+k}=C Q_{t+k-1}+B Z_{t+k}^{*}= \\
=C A^{k} Q_{t-1}+C \sum_{j=0}^{k-1} A^{j} B\left(\Phi^{k-j} Z_{t-1}^{*}+\sum_{m=0}^{k-1-j} \Phi^{m} \Psi_{t+k-1-j-m}\right)+B \Phi^{k+1} Z_{t+1}^{*}+B \sum_{j=0}^{k} \Phi^{j} \Psi_{t+k-j}
\end{gathered}
$$

An expression for the unpredictable forecast errors defined in (13), will be given by:

$$
\begin{gathered}
Q_{t+k}-E_{t}\left(Q_{t+k} \mid \Omega_{t}\right)=\sum_{j=0}^{k} A^{j} B\left(\sum_{m=0}^{k-j} \Phi^{m} \Psi_{t+k-j-m}\right) \\
Y_{t+k}-E_{t}\left(Y_{t+k} \mid \Omega_{t}\right)=C \sum_{j=0}^{k-1} A^{j} B\left(\sum_{m=0}^{k-1-j} \Phi^{m} \Psi_{t+k-1-j-m}\right)+B \sum_{j=0}^{k} \Phi^{j} \Psi_{t+k-j}
\end{gathered}
$$

Expressions (41) and (42) show that forecast errors are a weighted sum of current and future innovations summarized in the vector $\Psi_{t}$. Since, by assumption, these innovations are uncorrelated over time, these forecast errors are uncorrelated ${ }^{24}$ with variables in the (restricted) vector $Z_{t-h}$ for $h=1,2, \ldots$ Moreover, given assumption (38), then $Z_{t-h}$ is also uncorrelated with the policy shock.

\footnotetext{
${ }^{24}$ The contemporaneous vector of variables $Z_{t}$, however, is correlated with the forecast errors.
} 
Therefore, GMM estimation can be based on the moment condition:

$$
E_{t}\left[\left(i_{t}-\rho i_{t-1}+(1-\rho)\left(\alpha+\alpha_{\pi}\left(\pi_{t+k}-\pi_{t+k}^{*}\right)+\alpha_{y} y_{t}\right)\right) Z_{t-h} \mid \Omega_{t}\right]=E_{t}\left(\zeta_{t} Z_{t-h}\right)=0 \quad h=1,2, \ldots
$$

where $\zeta_{t}$ is the weighted sum of (unpredictable) forecast errors given by (41) and (42) and of the policy shock $v_{t}$.

\subsection{Instruments Used in Estimation of Forward Looking Rule, Autocorrelated Policy Shocks (Model I)}

The framework outlined in the previous section was used in the econometric procedure, as a guideline to chose instruments and corresponding valid moment conditions. Since the model was highly stylized, the proposed instruments were also generic concepts such as the international price of tradable goods. In the construction of the data set used in the paper, a proxy for these stylized variables was used. For example, in the case of international traded goods inflation, several types of international commodity price inflation was used. In what follows, the actual data used in the estimation is detailed.

(a) Sector specific productivity shocks. The proxy used was an average (over four quarters) of the quarterly, seasonally adjusted, rate of growth (at annual rate) of output per hour worked in the manufacturing sector, in the United States and in the United Kingdom. ${ }^{25}$

(b) The international prices of tradable goods. In this case, data on commodity price inflation, collected by the Commodity Research Bureau, was used. More specifically, quarterly averages of monthly price indexes were constructed and then the inflation rate between a given quarter, and the same quarter in the previous year, was computed. This was done for the general commodity price index, and for the "raw industrials", "metals" and "energy" subindexes.

\footnotetext{
${ }^{25}$ Data availability prevented the use of other country specific data.
} 
(c) Foreign demand for domestic exports. This is the category in which a more broad set of proxies was used. The approach was to select variables that are informative about global economic conditions. The variables selected were: (HP filtered), seasonally adjusted measures of industrial capacity utilization in the US, and of the unemployment rate in the US and in the European Monetary Union; the real growth rate of manufacturing production in the US and in the European Monetary Union, between a given quarter, and the same quarter in the previous year. Finally, to capture bullish and bearish tendencies in international markets, the four quarters percentage change in world and region specific Morgan Stanley MSCI Stock market index was included in the list of regressors.

(d) World interest rates. In this category as well as in the others, the focus was on data from "large economies" like the United States and the European Monetary Union. The spread between 3 month and 10 year US Treasury bonds was used, as well as the levels of interest rates of the 10 year bonds. ${ }^{26}$ The same type of data on spreads and interest rate levels for Euro denominated bonds issued by Governments within the EMU area were also used. Notice that the US federal funds rate and the ECB main refinancing operations rate are not initially included in this list of instrument. Their inclusion happens only when the possibility of policy contagion is investigated, in which case they are also included as additional regressors.

(e) Country risk premia. It is quite challenging to measure this variable given that interest rate differentials also depend significantly on expected exchange rate movements. The approach followed here was to use variables that might indicate changes in the investors appetite for risk. Two measures were used: the interest rate spread between bonds issued by US investment grade companies and "high yield" bonds, based on the Merrill Lynch aggregate indexes; the JP Morgan (Brady Bonds) Emerging Markets Bond (EMBI) Spreads. ${ }^{27}$

\footnotetext{
${ }^{26}$ There is now a large literature on the ability that these variables have to predict real growth and inflation. See, for instance, Kozicki (1997).

${ }^{27} \mathrm{JP}$ Morgan has a wide variety of regional EMBI spreads, but the Brady series is the one that dates back since early nineties, which was a requirement for the current estimation purposes.
} 


\subsection{Country Specific Data, Sources and Instruments}

\subsubsection{Australia}

\section{Instruments Used in Estimation of Model I}

Lagged (t-1) value of the following variables:

- International commodity price inflation (general index, energy and raw industrials)

- US data (productivity (output per hour worked, s.a.), unemployment (HP filtered, s.a.), capacity utilization, manufacturing production index, 10 year Government bond yields, bond spreads (corporate high yield minus investment grade; 10 year Government bond yields - 3 months T-bill)

- MSCI Asia Equity Index

- EMBI (Brady) spread

\section{Instruments Used in Estimation of Model II}

- Inflation deviation from the target (1,2 and 3 lags)

- HP filtered unemployment rate (1,2 and 3 lags)

- Policy Interest Rate (1,2,3, and 4 lags)

\section{Inflation Index}

CPI inflation, excluding most volatile items. Source: Reserve Bank of Australia.

\section{Unemployment Gap}

Unemployment rate (quarterly average), s.a., HP filtered. Source: Datastream and Bloomberg (Labor Force Survey estimate)

\section{Interest "Policy" Rate}

Reserve Bank of Australia Cash Rate. Source: Reserve Bank of Australia.

\subsubsection{Canada}

\section{Instruments Used in Estimation of Model I}

Lagged ( $\mathrm{t}-1)$ value of the following variables: 
- International commodity price inflation (general index and raw industrials)

- US data (productivity (output per hour worked, s.a.), unemployment (HP filtered, s.a), capacity utilization, manufacturing production index, 10 year Government bond yields, bond spreads (corporate high yield minus investment grade; 10 year Government bond yields - 3 months T-bill)

- US Dollar x Canadian Dollar and US Dollar x Mexican Peso nominal exchange rate changes (4 quarters accumulated percentage changes, based on quarterly figures, constructed as an average of monthly end of period nominal exchange rates).

\section{Instruments Used in Estimation of Model II}

- Inflation deviation from the target (1,2, 3 and 4 lags)

- HP filtered unemployment rate (1,2,3 and lags)

- Policy Interest Rate (1 lag)

\section{Inflation Index}

Core CPI inflation. Source: Bank of Canada.

\section{Unemployment Gap}

Unemployment rate (quarterly average), s.a., HP filtered. Source: Bank of Canada.

\section{Interest "Policy" Rate}

"Bank Rate" until February 1996, defined as the average yield of the Bank's weekly auction of 3 month T-Bill. Bank of Canada target overnight rate henceforth. Source:

Bank of Canada.

\subsubsection{Chile}

\section{Instruments Used in Estimation of Model I}

Lagged (t-1) value of the following variables:

- International commodity price inflation (general index, energy and raw industrials) 
- US data (productivity (output per hour worked, s.a.), unemployment (HP filtered, s.a.), capacity utilization, manufacturing production index, 10 year Government bond yields, bond spreads (10 year Government bond yields - 3 months T-bill)

- MSCI World Equity Index

- EMBI (Brady) spread

\section{Instruments Used in Estimation of Model II}

- Inflation deviation from the target (1,2, 3 and 4 lags)

- HP filtered unemployment rate (1,2,3 and lags)

- Policy Interest Rate (1,2,3 and lags)

\section{Inflation Index}

Headline CPI. Source: Central Bank of Chile.

\section{Unemployment Gap}

Unemployment rate (quarterly average), s.a., nationwide measure, HP filtered. Source: Central Bank of Chile (National Statistic Bureau)

\section{Interest "Policy" Rate}

Until April 1995, the nominal return on 3 month T-bills (PRBC). Nominal return computed based on real return (raw data) plus official rate used to compute nominal returns (Unidad de Fomento - UF). After April 1995: Central Bank Monetary Policy Rate. As before, nominal rate computed by adding the percentage variation in UF. In August 2001, the monetary policy rate started being announced in nominal terms.

\subsubsection{New Zealand}

\section{Instruments Used in Estimation of Model I}

Lagged ( $\mathrm{t}-1)$ value of the following variables:

- International commodity price inflation (general index) 
- US data (productivity (output per hour worked, s.a.), unemployment (HP filtered, s.a.), capacity utilization, manufacturing production index (HP filtered, s.a.), 10 year Government bond yields, bond spreads (10 year Government bond yields - 3 months T-bill)

- US Dollar x New Zealand Dollar nominal exchange rate (4 quarters accumulated percentage changes, based on quarterly figures, constructed as an average of monthly end of period nominal exchange rates).

- MSCI World Equity Index

\section{Instruments Used in Estimation of Model II}

- Inflation deviation from the target $(1,2,3$ and 4 lags)

- HP filtered unemployment rate (1,2,3 and lags)

- Policy Interest Rate $(1,2,3$ and lags $)$

\section{Inflation Index}

Headline CPI. Source: New Zealand Central Bank.

\section{Unemployment Gap}

Unemployment rate (quarterly data), seasonally adjusted, HP filtered. Source: New Zealand Central Bank.

\section{Interest "Policy" Rate"}

Official Cash Rate.

Real-time Central Bank's Forecasts Quarterly headline CPI and output gap forecasts. Source: New Zealand Central Bank. Forecasts correspond to the expected value of these variables at year $\mathrm{t}+1, \mathrm{t}+2$, etc. K-quarters ahead forecasts were constructed based on a weighted average of these yearly figures. 


\subsubsection{Sweden}

\section{Instruments Used in Estimation of Model I}

Lagged (t-1) value of the following variables:

- International commodity price inflation (energy and raw industrials)

- US data (HP filtered, s.a., unemployment, manufacturing production index)

- US Dollar x Swedish Krona nominal exchange rate (4 quarters accumulated percentage changes, based on quarterly figures, constructed as an average of monthly end of period nominal exchange rates).

- EMU data (productivity, HP filtered, s.a., unemployment, 10 year Euro 11 - Government bond yields, bond spreads (10 year Euro 11 - Government bond yields - 3 months T-bill). Source: Eurostat.

- UK productivity (output per hour worked, s.a). Source: Statistics UK.

\section{Instruments Used in Estimation of Model II:}

- Inflation deviation from the target (1,2, 3 and 4 lags)

- HP filtered unemployment rate (1,2,3 and lags)

- Policy Interest Rate (1,2,3 and lags)

\section{Inflation Index}

Headline CPI. Source: Riksbank (Statistics Sweden).

\section{Unemployment Gap}

Unemployment rate (quarterly average), seasonally adjusted, HP filtered. Source: Statistics Sweden.

\section{Interest "Policy" Rate}

Riksbank Repo Rate.

\section{Real-time Central Bank's Forecasts}

Headline CPI and output growth forecasts. Source: Riksbank. Forecasts correspond to the ex- 
pected value of these variables at year $t+1, t+2$, etc. K-quarters ahead forecasts were constructed based on a weighted average of these yearly figures.

\subsubsection{United Kingdom}

\section{Instruments Used in Estimation of Model I}

Lagged (t-1) value of the following variables:

- International commodity price inflation (general index, energy and raw industrials)

- US data (unemployment (HP filtered, s.a.), capacity utilization, 10 year Government bond yields, bond spreads (corporate high yield minus investment grade; 10 year Government bond yields - 3 months T-bill).

- MSCI World Equity Index

- EMU data: bond spreads (10 year Euro 11 Government bond yields - 3 months T-bill), unemployment rate (HP filtered, s.a.).

- Pound x Euro nominal exchange rate (4 quarters accumulated percentage changes, based on quarterly figures, constructed as an average of monthly end of period nominal exchange rates).

\section{Instruments Used in Estimation of Model II}

- Inflation deviation from the target (1,2, 3 and 4 lags)

- HP filtered unemployment rate (1,2,3 and lags)

- Policy Interest Rate (1,2,3 and lags)

\section{Inflation Index}

RPIX until December 2003, headline CPI henceforth.

\section{Unemployment Gap}

Unemployment rate (quarterly average), seasonally adjusted, HP filtered. Source: Statistics UK.

\section{Interest "policy rate"}

Bank of England Base Rate: Source: Bank of England. 


\section{Real-time Central Bank's Forecasts}

RPIX, headline CPI and output growth forecasts. Source: Bank of England. Data corresponds to K-quarters ahead forecasts of the percentage increase in prices/output over a year earlier.

\subsubsection{United States}

\section{Unemployment Gap}

Constructed based on the difference between the unemployment rate (real-time data) and the real-time estimate of the NAIRU. For example, in 1991 Q1, there was real-time data available regarding the unemployment rate in 1990 Q4. There was also the 1991 vintage of NAIRU estimate corresponding to 1990 Q4. The constructed 1991 Q1 observation for the unemployment gap consists in the difference between these two measures. Sources: NAIRU - Kozicki (2004); Unemployment rate: Federal Reserve Bank of Philadelphia Real Time Data Set.

\section{Interest "Policy" Rate}

Federal Funds Rate Target. Source: Board of Governors of the Federal Reserve System.

\section{Real-time Central Bank's Forecasts}

Federal Reserve Greenbook Forecasts for the GNP/GDP price level (up to 1999 Q4). From 2000 Q1 to 2004 Q4, the proxy used for the Greenbook forecasts (which are only available with a lag of 5 years) was data from the Survey of Professional Forecasters. The two series display a very high correlation. Raw Greenbook data corresponds to quarter over quarter percentage changes, at an annual rate. Data used is the average rate between $(t+1)$ and $(t+4)$. Source: Federal Reserve Bank of Philadelphia Real Time Data Set. 


\section{References}

[1] Ambler, S., Dib, A. and Rebei, N. (2004), "Optimal Taylor Rules in an Estimated Model of a Small Open Economy", Working Paper 2004-36, Bank of Canada.

[2] Andrews, D. and Monahan, C. (1992), "An Improved Heteroskedasticity and Autocorrelation Consistent Covariance Matrix Estimation", Econometrica, 60, pp. 953-966.

[3] Batini, N. and Haldane, A. (1999), "Forward-looking rules for monetary policy". in: Taylor, J. (Editor), Monetary Policy Rules, The University of Chicago Press, Chicago.

[4] Batini, N. and Nelson, E. (2001), "Optimal Horizons for Inflation Targeting", Journal of Economic Dynamics and Control, Vol. 25 pp. 891 - 210, 2001.

[5] Bernanke, B. and Boivin, J. (2003), "Monetary Policy in a Data-Rich Environment", Journal of Monetary Economics, 50:3, pp. 525 - 546, 2003.

[6] Bernanke, B. and Mishkin, F. (1997), "Inflation Targeting: A New Framework for Monetary Policy?", Journal of Economic Perspectives, Vol. 11 pp. 97 - 116, 1997.

[7] Berg, C. , Jansson, P. and Vredin, A. (2004), "How Useful are Simple Rules for Monetary Policy? The Swedish Experience", Working Paper Series 169, Sveriges Riksbank.

[8] Céspedes, L. \& Soto, C. (2004), "Credibility and Inflation Targeting in an Emerging Market: The Case of Chile", Working Paper Series 312, Central Bank of Chile.

[9] Clarida, R., Gali, J. and Gertler, M. (1998), "Monetary Policy Rules in Practice: Some International Evidence", European Economics Review, pp. 1033-1068, June 1998.

[10] Croushore, D. \& Stark, T. (2001), "A Real-Time Data Set for Macroeconomists", Journal of Econometrics 105 (November 2001), pp. 111-130.

[11] Cushing, M. and McGarvey, M. (1999), "Covariance Matrix Estimation”, in: Mátyás, L. (ed.), Generalized Method of Moments Estimation, Cambridge University Press, Cambridge, 1999. 
[12] Debelle, G. and Wilkinson, J. (2002), "Inflation Targeting and the Inflation Process: Some Lessons from an Open Economy", Research Discussion Paper 2002-01, Reserve Bank of Australia.

[13] de Brouwer,G. and Ellis, L. (1998), "Forward Looking Behavior and Credibility: Some Evidence and Implications for Policy", Research Discussion Paper 9803, Reserve Bank of Australia.

[14] Faust, J. and Henderson, D. (2004), "Is Inflation Targeting Best-Practice Monetary Policy?", International Finance Discussion Papers, Number 807, Board of Governors of the Federal Reserve System, May 2004.

[15] Freitas, P. , Goldfajn, I. , Minella, A. , Muinhos, M. (2003), "Inflation Targeting in Brazil: Constructing Credibility under Exchange Rate Volatility", Journal of International Money and Finance 22 (2003), pp. 1015 - 1040.

[16] Friedman, B. (2004), "Why the Federal Reserve Should Not Adopt Inflation Targeting?", International Finance, 7 (1), pp. 129 - 136.

[17] Greene, W. (2000), "Econometric Analysis", 4th Edition, Prentice Hall International, London.

[18] Hendry, S., Ho, W. and Moran, K. (2003), "Simple Monetary Policy Rules in an Open Economy, Limited Participation Model", Working Paper 2003-38, Bank of Canada.

[19] King, M. (1997), "Changes in UK Monetary Policy: Rules and Discretion in Practice", Journal of Monetary Economics, 39:1, pp. 81 - 97, 1997.

[20] Kozicki, S. (1997), "Predicting Real Growth and Inflation with the Yield Spread", Federal Reserve Bank of Kansas City Economic Review Article, Fourth Quarter 1997.

[21] Kozicki, S. (2004), "How Do Data Revision Affect the Evaluation and Conduct of Monetary Policy?", Federal Reserve Bank of Kansas City Economic Review Article, First Quarter 2004.

[22] Kuttner, Kenneth (2004), "The Role of Policy Rules in Inflation Targeting", Oberlin College, working paper. 
[23] Levin, A., Wieland, W. and Williams, J. (2003), "The Performance of Forecast-Based Monetary Policy Rules under Model Uncertainty", American Economic Review, 93(3), pp. 622 - 645.

[24] Leitemo, K. (2005), "Targeting Inflation by Forecast Feedback Rules in Small Open Economies", Journal of Economic Dynamics and Control, forthcoming.

[25] Lubik, T. and Schorfheide, F. (2003), "Do Central Banks Respond to Exchange Rates? A Structural Investigation", working paper.

[26] Obstfeld, M. and Rogoff, K. (2002), "Global Implications of Self-Oriented National Rules", Quarterly Journal of Economics, 117 (2), pp. 503 - 535, May 2002.

[27] McCallum, B. and Nelson, E. (2004) "Targeting vs. Instrument Rules for Monetary Policy" Federal Reserve Bank of St. Louis Working Paper 2004-011A.

[28] Mishkin, F. (2004), "Why the Federal Reserve Should Adopt Inflation Targeting?", International Finance, 7 (1), pp. 117 - 127.

[29] Orphanides, A. (2001), "Monetary Policy Rules Based on Real Time Data", American Economic Review, 91(4), pp. 964 - 985, September 2001.

[30] Poole, W. (2003), "Fed Transparency: How, Not Whether", Luncheon address before the Global Interdependence Center, Federal Reserve Bank of Philadelphia, Aug. 21, 2003

[31] Rudebusch, G. and Svensson, L. (1999), "Policy Rules for Inflation Targeting", in: Taylor, J. (Editor), Monetary Policy Rules, The University of Chicago Press, Chicago.

[32] Rudebusch, G. (2002), "Term Structure Evidence on Interest Rate Smoothing and Monetary Policy Inertia", Journal of Monetary Economics, 49:6, pp. 1161 - 1187, 2002.

[33] Ryan, C. and Thompson, C. (2000), "Inflation Targeting and Exchange Rate Fluctuations in Australia", Research Discussion Paper 2000-06, Reserve Bank of Australia.

[34] Shea, J. (1997), "Instrument Relevance in Multivariate Linear Models: A Simple Measure", The Review of Economics and Statistics, Vol. 79 (2). pp. 348 - 352. 
[35] Stock, J., Wright, J. and Yogo, M. (2002), "A Survey of Weak Instruments and Weak Identification in Generalized Method of Moments", Journal of Business 83 Economic Statistics, 20(4), pp. $518-530$.

[36] Svensson, L. (1997), "Inflation Forecast Targeting: Implementing and Monitoring Inflation Targets", European Economic Review 41, pp.1111-1146, 1997.

[37] Svensson, L. (1999), "Inflation Targeting as a Monetary Policy Rule", Journal of Monetary Economics, 43:3, pp. 607 - 654, 1999.

[38] Svensson, L. (2005), "Monetary Policy with Judgement: Forecast Targeting", paper presented at the conference on Dynamic Models and Monetary Policymaking, Federal Reserve Bank of Cleveland, September 22-24, 2004.

[39] Taylor, J. (1993), "Discretion versus Policy Rules in Practice", Carnegie-Rochester Conference Series on Public Policy, 39, pp. 195 - 214, December 1993. 


\section{Figures and Tables}

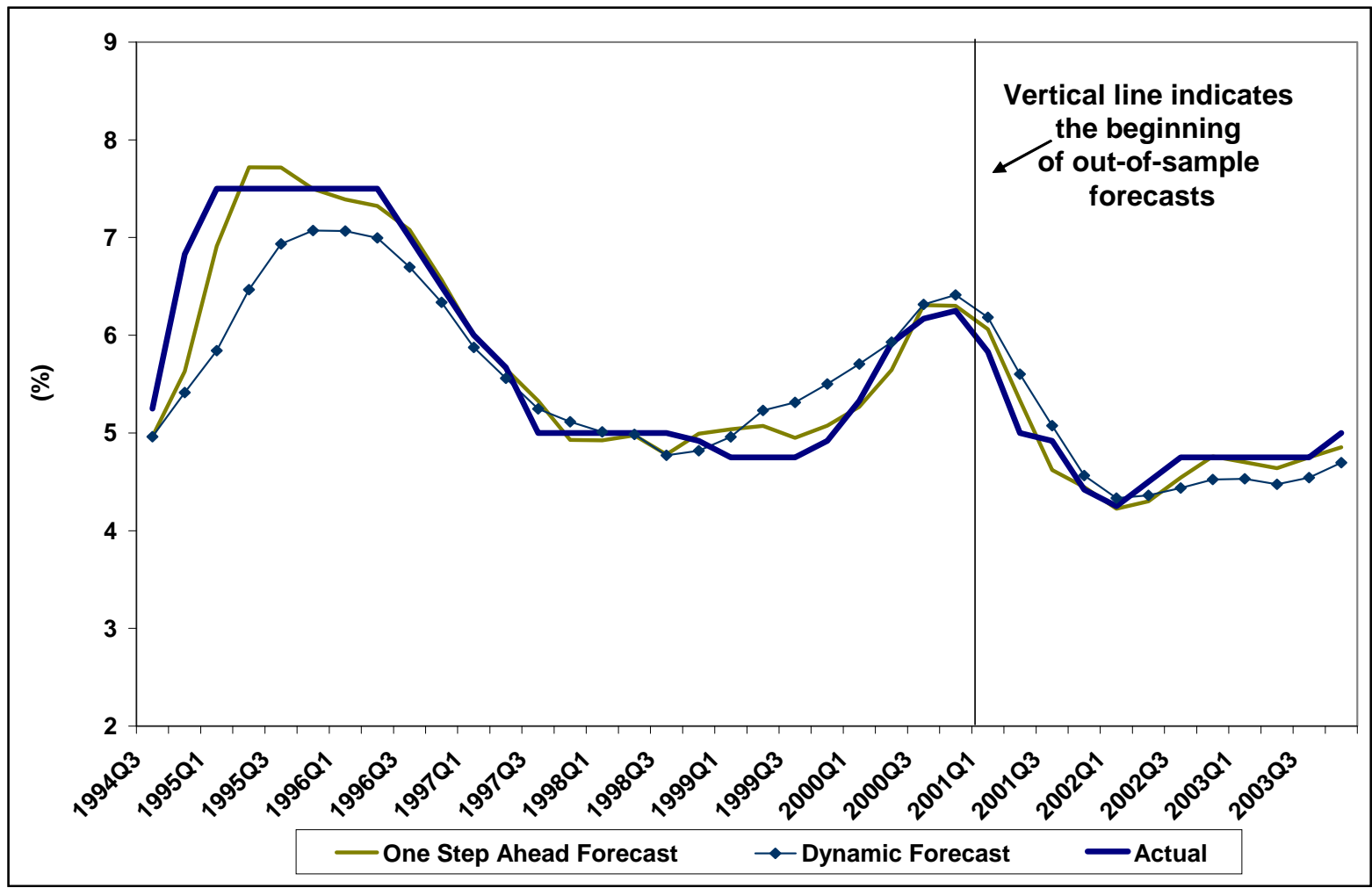

Figure 1: Australia - Actual and Fitted Reserve Bank of Australia Cash Rate - Fitted values based on forward looking rule, autocorrelated disturbances model I. 


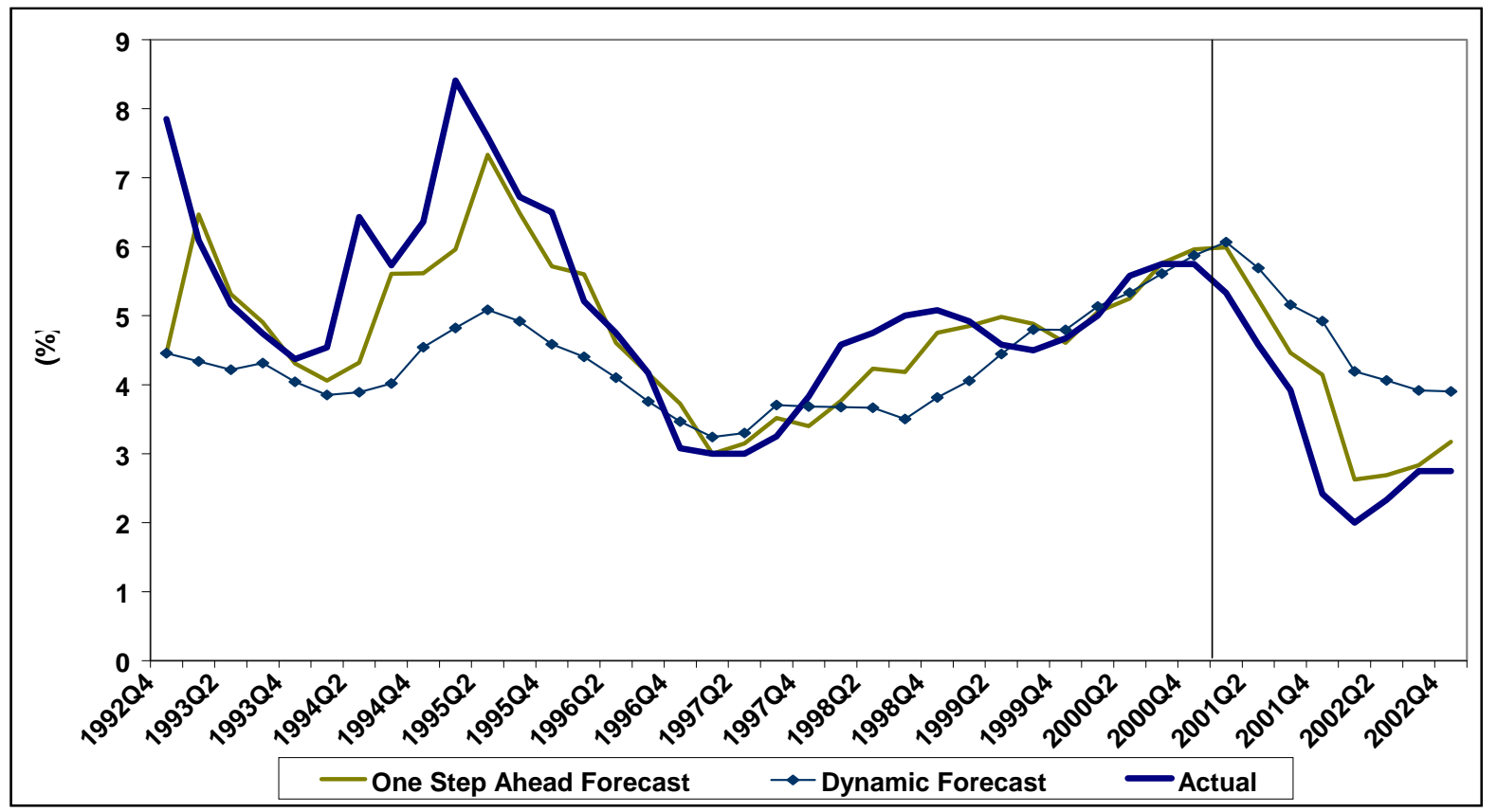

Figure 2: Canada - Actual and Fitted Bank of Canada Overnight Target Rate - Fitted values based on forward looking rule, autocorrelated disturbances (model I).

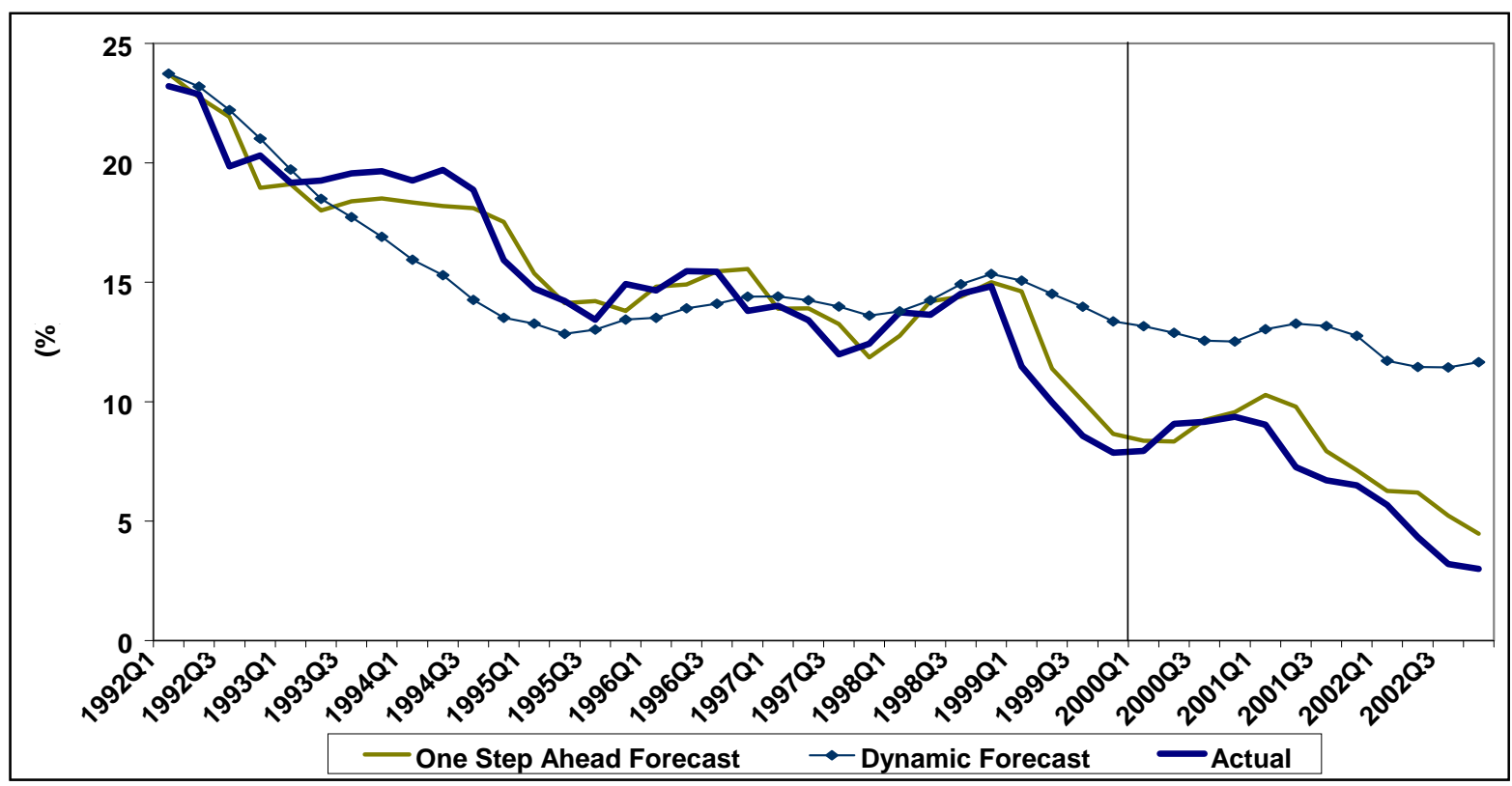

Figure 3: Chile - Actual and Fitted Central Bank of Chile Monetary Policy Rate (TPM) - Fitted values based on forward looking rule, autocorrelated disturbances (model I). 


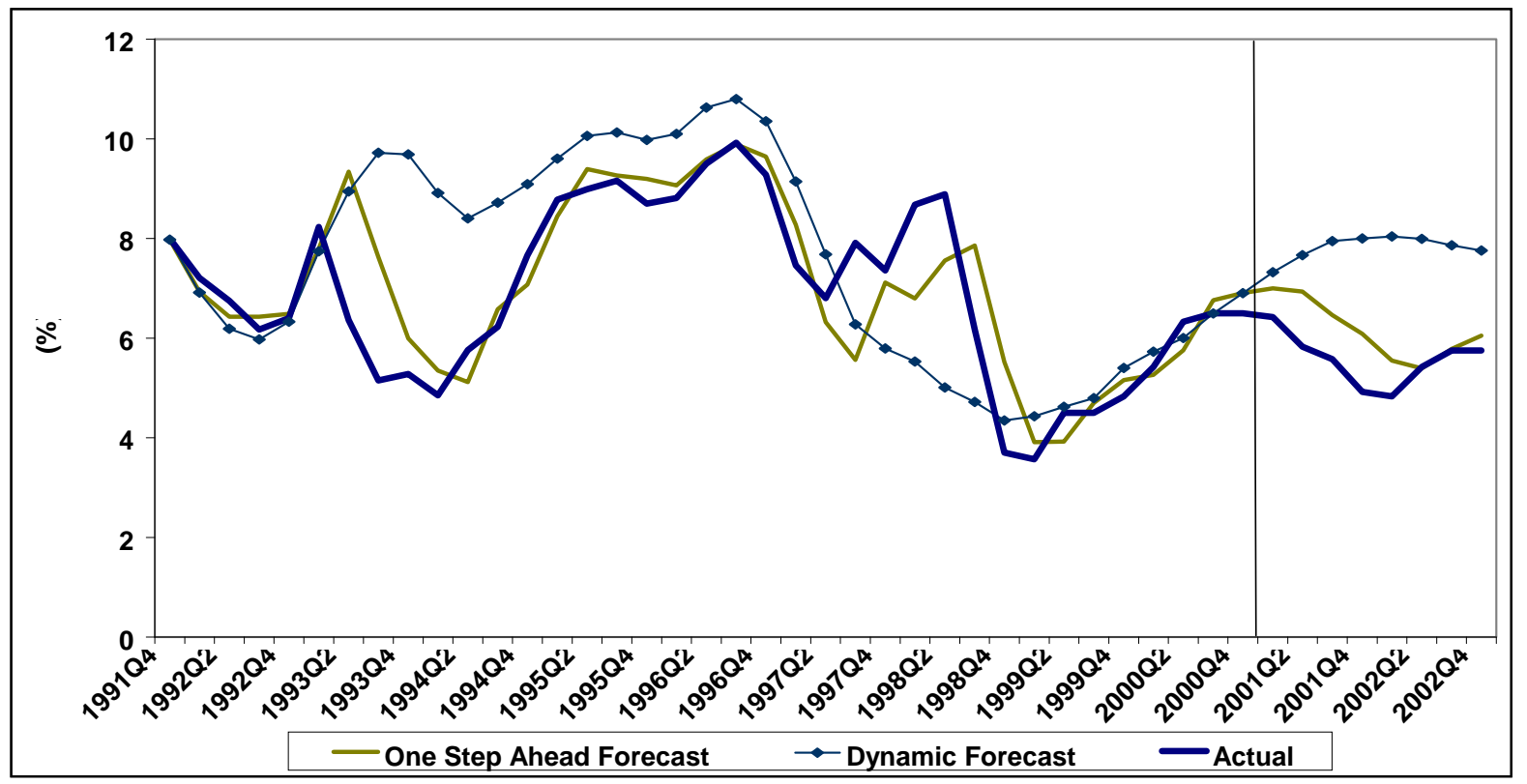

Figure 4: New Zealand - Actual and Fitted Reserve Bank of New Zealand Cash Rate - Fitted values based on forward looking rule, autocorrelated disturbances (model I).

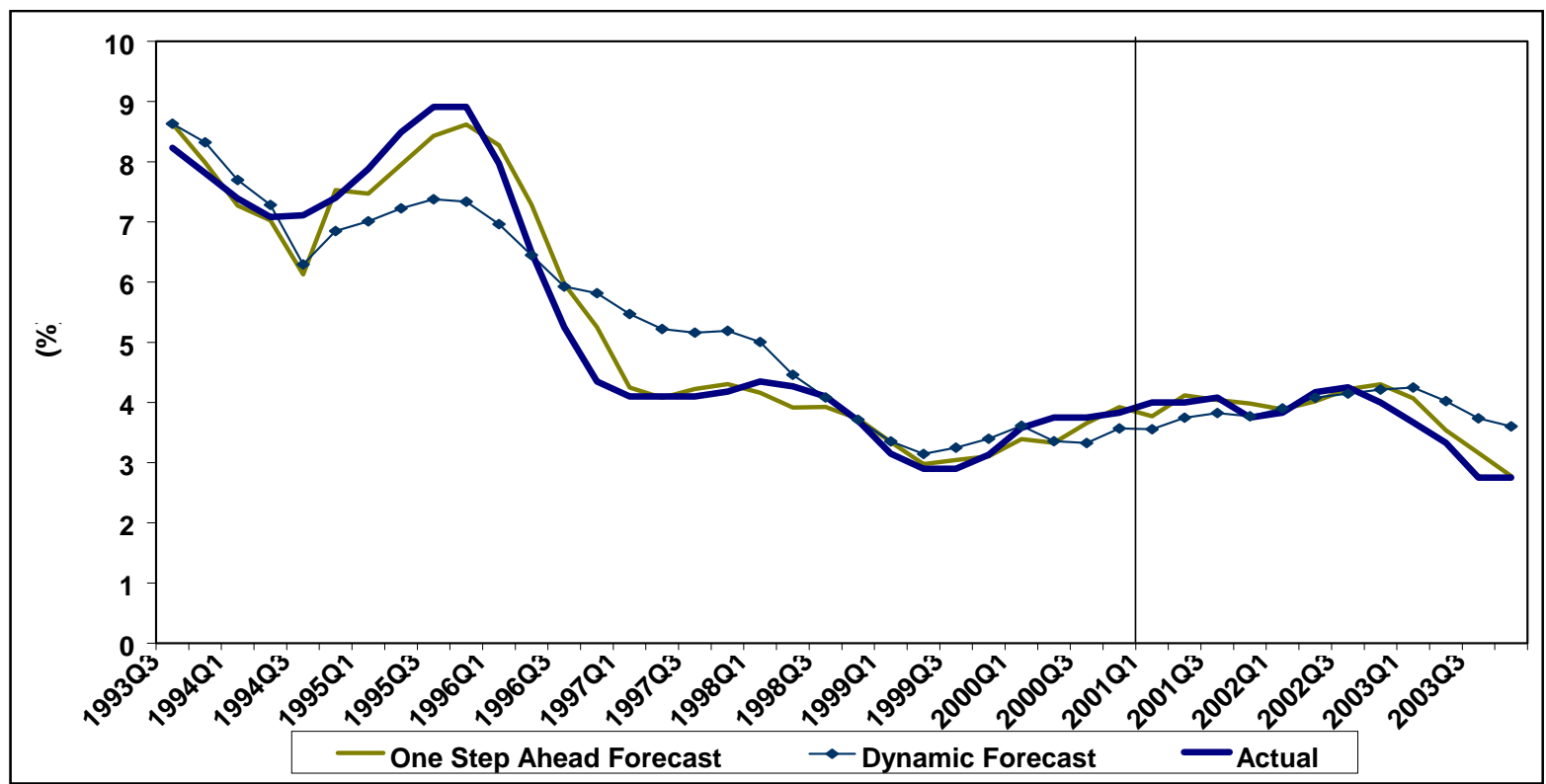

Figure 5: Sweden - Actual and Fitted Central Bank of Sweden Repo Rate - Fitted values based on forward looking rule, real time inflation and growth forecasts (model IV). 


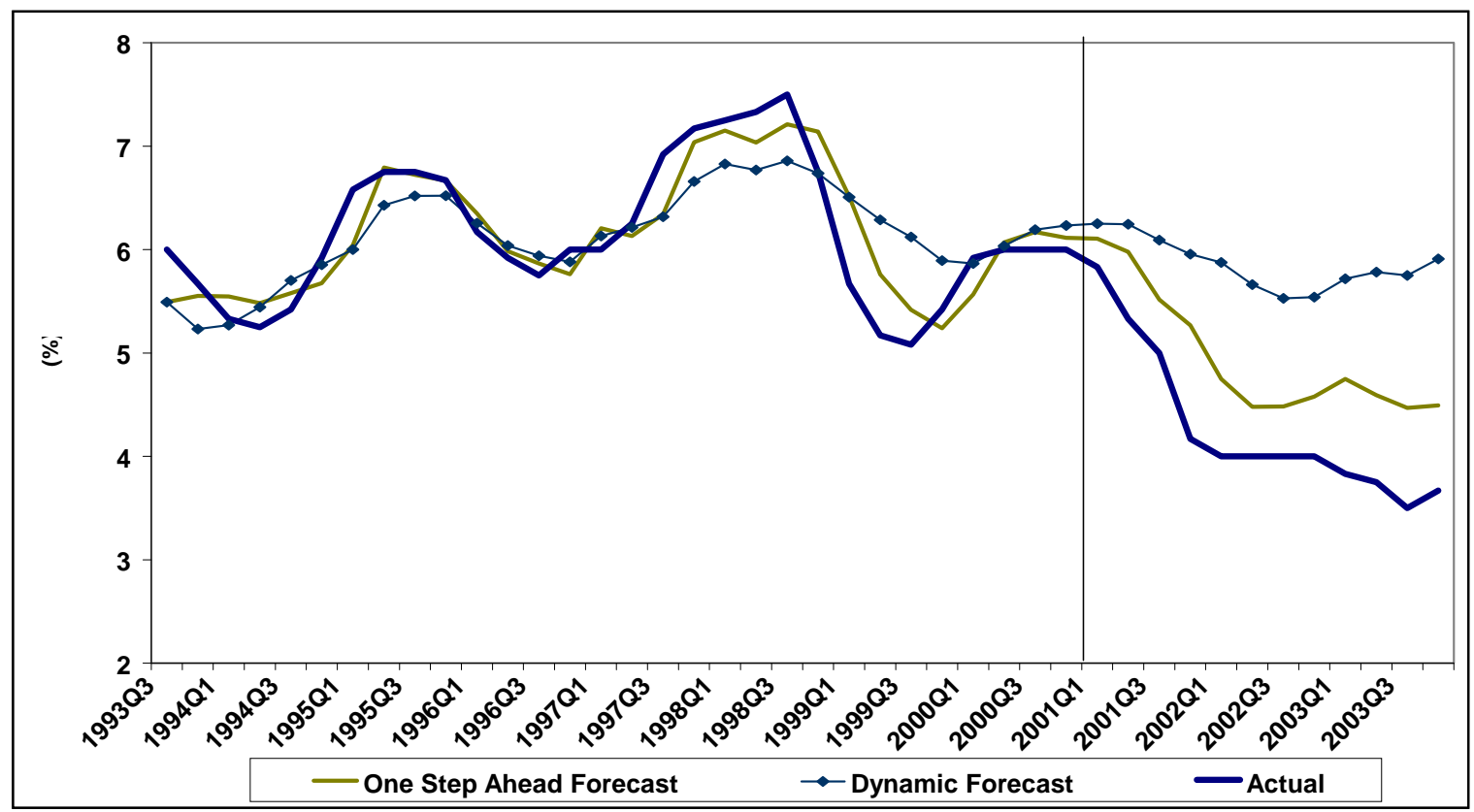

Figure 6: United Kingdom - Actual and Fitted Bank of England Base Rate - Fitted values based on forward looking rule, real time inflation forecasts (model III).

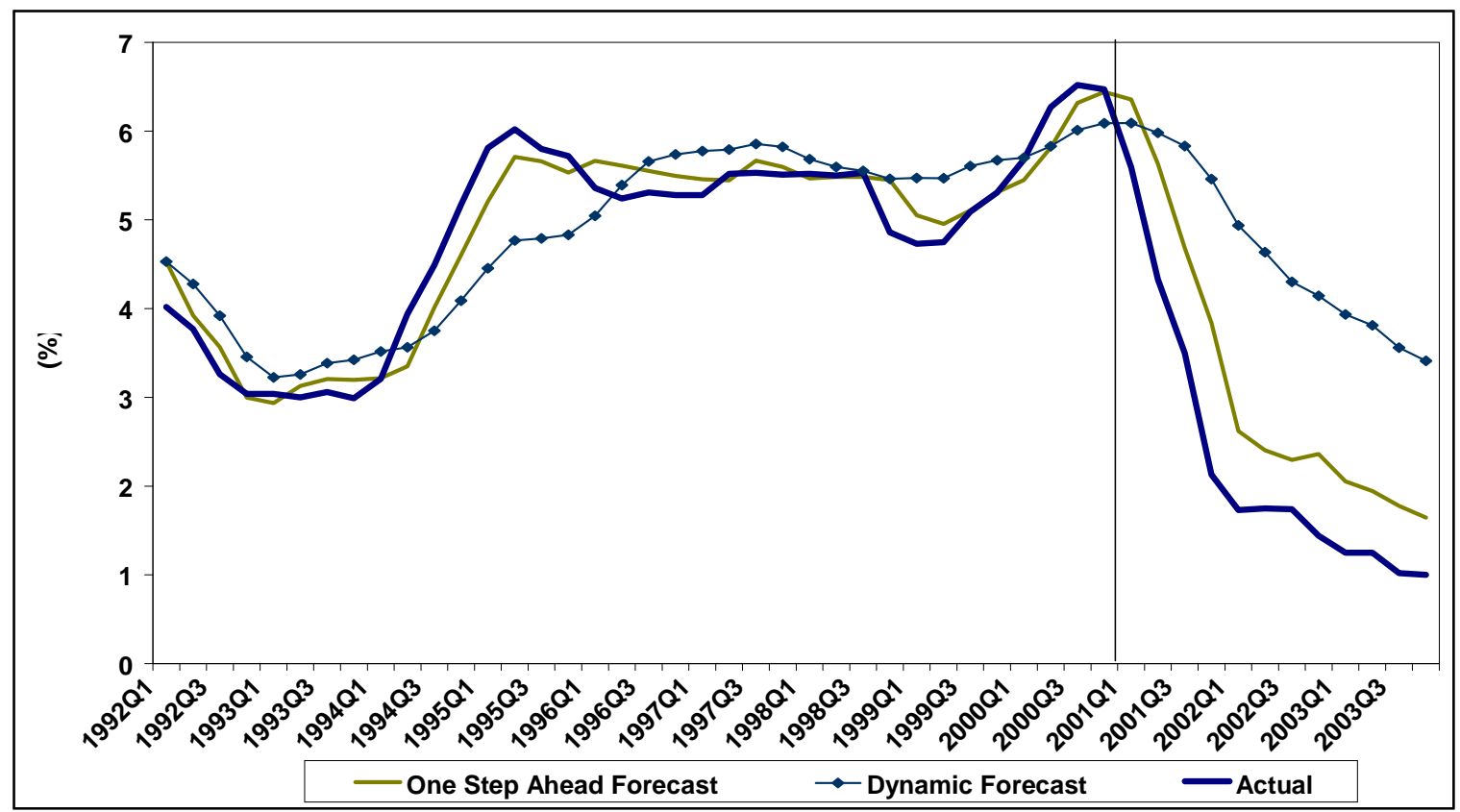

Figure 7: United States - Actual and Fitted Federal Funds Rate Target - Fitted values based on forward looking rule, real time unemployment data and inflation forecasts (model III). 


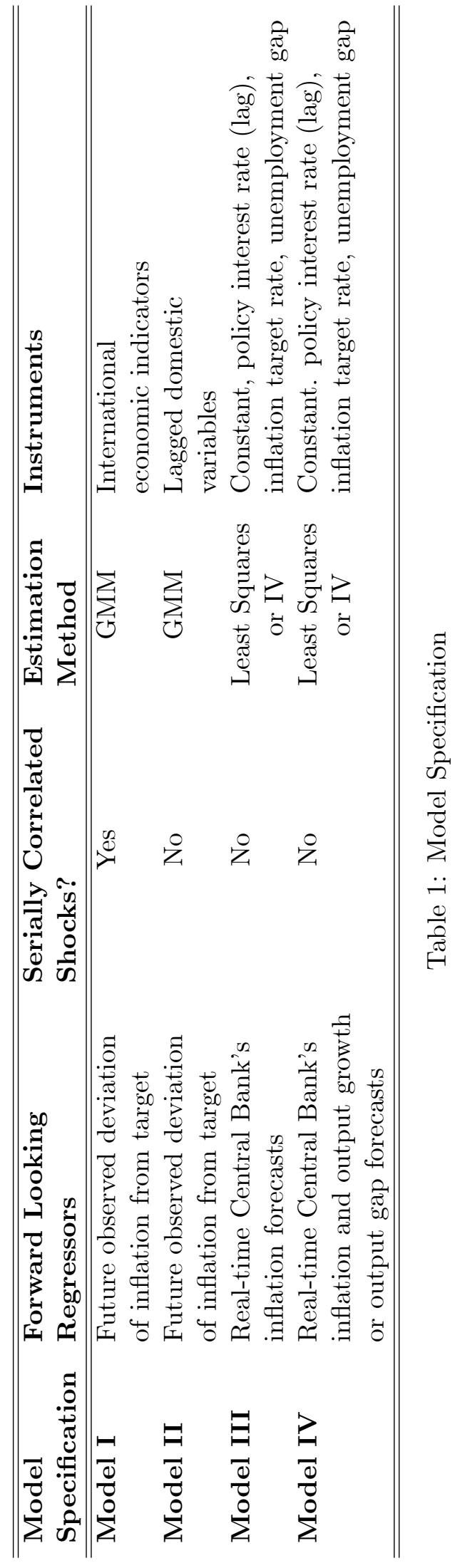




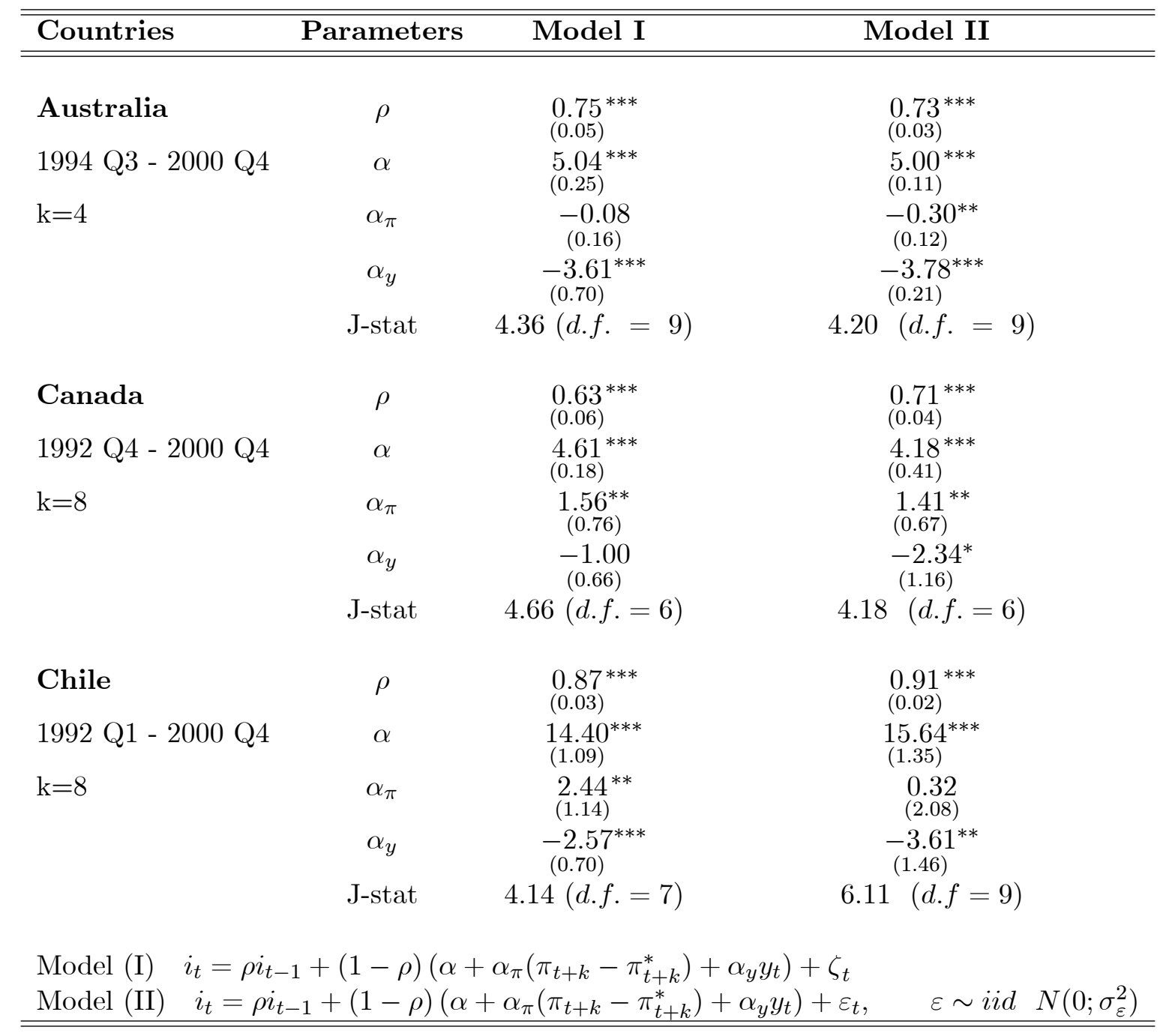

Table 2: Forward Looking Rules ( $\mathrm{k}=$ forecast horizon) - Parameter Estimates 


\begin{tabular}{|c|c|c|c|c|c|}
\hline Countries & Parameters & Model I & Model II & Model III & Model IV \\
\hline New Zealand & $\rho$ & $\begin{array}{l}0.80^{* * *} \\
(0.04)\end{array}$ & $\begin{array}{l}0.79^{* * *} \\
(0.07)\end{array}$ & $\begin{array}{l}0.17 \\
(0.57)\end{array}$ & $\begin{array}{l}0.18 \\
(0.52)\end{array}$ \\
\hline $1991 \mathrm{Q} 4-2000 \mathrm{Q} 4$ & $\alpha$ & $\begin{array}{l}7.46^{* * *} \\
(0.43)\end{array}$ & $\begin{array}{l}7.77^{* * *} \\
(0.67)\end{array}$ & $\begin{array}{l}7.08^{* * *} \\
(0.43)\end{array}$ & $\begin{array}{l}7.13 \\
(0.51)\end{array}$ \\
\hline (models I and II) $\mathrm{k}=8$ & $\alpha_{\pi}$ & $\begin{array}{l}4.54^{* *} \\
(2.11)\end{array}$ & $\begin{array}{l}5.98 \\
(4.21)\end{array}$ & $\begin{array}{l}1.92^{* *} \\
(0.64)\end{array}$ & $\begin{array}{l}1.93^{* *} \\
(0.68)\end{array}$ \\
\hline 1997 Q2 - 2000 Q4 & $\alpha_{y}$ & $\begin{array}{l}-4.61^{* * *} \\
\quad(1.25)\end{array}$ & $\begin{array}{l}-4.21^{* *} \\
(1.85)\end{array}$ & $\begin{array}{l}-0.27 \\
(1.28)\end{array}$ & $\begin{array}{l}0.15 \\
(0.83)\end{array}$ \\
\hline (models III and IV) & J-stat & $3.64 \quad(d . f .=5)$ & $2.76(d . f .=9)$ & & \\
\hline Sweden & $\rho$ & $\begin{array}{l}0.84^{* * *} \\
(0.11)\end{array}$ & $\begin{array}{c}0.90^{* * *} \\
(0.06)\end{array}$ & $\begin{array}{l}0.78^{* * *} \\
(0.07)\end{array}$ & $\begin{array}{l}0.83^{* * *} \\
(0.07)\end{array}$ \\
\hline 1993 Q3 - 2000 Q4 & $\alpha$ & $\begin{array}{c}4.70^{* * *} \\
(0.74)\end{array}$ & $\begin{array}{c}5.49^{* * *} \\
(2.43)\end{array}$ & $\begin{array}{l}4.69^{* * *} \\
(0.28)\end{array}$ & $\begin{array}{l}1.46 \\
(2.68)\end{array}$ \\
\hline \multirow[t]{3}{*}{$\mathrm{k}=4$} & $\alpha_{\pi}$ & $\begin{array}{l}0.37 \\
(0.73)\end{array}$ & $\begin{array}{l}0.91 \\
(1.97)\end{array}$ & $\begin{array}{l}2.38^{* * *} \\
(0.35)\end{array}$ & $\begin{array}{l}2.45^{* * *} \\
(0.58)\end{array}$ \\
\hline & $\alpha_{y}$ & $\begin{array}{l}0.003 \\
(1.55)\end{array}$ & $\begin{array}{l}-1.27 \\
(2.88)\end{array}$ & $\begin{array}{l}-1.22^{*} \\
(0.67)\end{array}$ & $\begin{array}{l}1.12 \\
(0.94)\end{array}$ \\
\hline & J-stat & $0.98(d . f .=6)$ & $3.21(d . f .=9)$ & & \\
\hline United Kingdom & $\rho$ & $\begin{array}{l}0.66^{* * *} \\
(0.05)\end{array}$ & $\begin{array}{l}0.46^{* * *} \\
(0.15)\end{array}$ & $\begin{array}{l}0.63^{* * *} \\
(0.13)\end{array}$ & $\begin{array}{l}1.13^{* * *} \\
(0.13)\end{array}$ \\
\hline 1993 Q3 - 2000 Q4: & $\alpha$ & $\begin{array}{l}6.04^{* * *} \\
(0.13)\end{array}$ & $\begin{array}{l}6.44^{* * *} \\
(0.14)\end{array}$ & $\begin{array}{l}5.94^{* * *} \\
(0.19)\end{array}$ & $\frac{12.76^{*}}{(6.50)}$ \\
\hline models I, II, III & $\alpha_{\pi}$ & $\begin{array}{l}1.06^{* *} \\
(0.41)\end{array}$ & $\begin{array}{l}-0.54 \\
(0.56)\end{array}$ & $\begin{array}{l}0.71^{* *} \\
(0.26)\end{array}$ & $\begin{array}{l}1.36 \\
(3.33)\end{array}$ \\
\hline 1997 Q3 - 2000 Q4: & $\alpha_{y}$ & $\begin{array}{l}-1.94^{* * *} \\
(0.43)\end{array}$ & $\begin{array}{l}-1.48^{* * *} \\
(0.21)\end{array}$ & $\begin{array}{l}-2.22^{* * *} \\
(0.58)\end{array}$ & $\begin{array}{l}-3.33 \\
(3.49)\end{array}$ \\
\hline $\begin{array}{l}\text { model IV } \\
\mathrm{k}=4\end{array}$ & J-stat & $5.40 \quad(d . f=9)$ & $1.52(d . f .=9)$ & & \\
\hline United States & $\rho$ & - & - & $\begin{array}{l}0.69^{* * *} \\
(0.08)\end{array}$ & - \\
\hline 1992 Q2 - 2000 Q4 & $\alpha$ & - & - & $\begin{array}{c}1.62 \\
(1.25)\end{array}$ & - \\
\hline $\mathrm{k}=4$ & $\alpha_{\pi}$ & - & - & $\begin{array}{l}1.44^{* *} \\
(0.56)\end{array}$ & - \\
\hline & $\alpha_{y}$ & 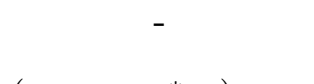 & - & $\begin{array}{l}-1.15^{* * *} \\
(0.16)\end{array}$ & - \\
\hline \multicolumn{6}{|c|}{ Model $(\mathrm{I}) \quad i_{t}=\rho i_{t-1}+(1-\rho)\left(\alpha+\alpha_{\pi}\left(\pi_{t+k}-\pi_{t+k}^{*}\right)+\alpha_{y} y_{t}\right)+\zeta_{t}$} \\
\hline \multicolumn{6}{|c|}{ Model (III) $i_{t}=\rho i_{t-1}+(1-\rho)\left[\alpha+\alpha_{\pi}\left(E_{t} \pi(\widetilde{i})_{t+k}-\pi_{t+k}^{*}\right)+\alpha_{y} y_{t}\right]+v_{t}$} \\
\hline Model (IV) $i_{t}=\rho i_{t-1}$ & $+(1-\rho)[\alpha+a$ & $\chi_{\pi}\left(E_{t} \pi(\widetilde{i})_{t+k}-\pi_{t+k}^{*}\right.$ & $+\alpha_{y} E_{t} y(\widetilde{i})_{t+k}$ & $+v_{t}$ & $i d \quad N\left(0 ; \sigma_{\nu}^{2}\right)$ \\
\hline
\end{tabular}

Table 3: Forward Looking Rules - Parameter Estimates (continued). Model IV uses Central Bank's output growth forecast (Sweden and United Kingdom) and output gap forecast (New Zealand) 


\begin{tabular}{|c|c|c|c|c|c|c|}
\hline $\begin{array}{l}\text { Countries/Parameters } \\
\end{array}$ & $\rho$ & $\alpha \alpha$ & $\alpha_{\pi}$ & $\alpha_{y}$ & $\begin{array}{l}\alpha_{i, U S} \\
\end{array}$ & $\alpha_{i, E C B}$ \\
\hline Australia (1994Q3 - 2000Q4) & $\begin{array}{l}0.76^{* * *} \\
(0.03)\end{array}$ & $\begin{array}{l}4.66^{* * *} \\
(0.15)\end{array}$ & $\begin{array}{l}-0.37^{* * *} \\
(0.08)\end{array}$ & $\begin{array}{l}-3.58^{* * *} \\
(0.57)\end{array}$ & $\begin{array}{l}1.93^{* * *} \\
(0.42)\end{array}$ & 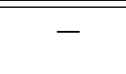 \\
\hline \multicolumn{7}{|l|}{ J-stat $4.98(d . f .=9)$} \\
\hline Canada (1992 Q4 - 2000 Q4) & \multirow[t]{2}{*}{$\begin{array}{l}0.69^{* * *} \\
(0.04)\end{array}$} & \multirow[t]{2}{*}{$\begin{array}{l}4.46^{* * *} \\
(0.24)\end{array}$} & \multirow[t]{2}{*}{$\begin{array}{l}1.55^{* *} \\
(0.76)\end{array}$} & \multirow[t]{2}{*}{$\begin{array}{l}-1.30 \\
(0.78)\end{array}$} & \multirow[t]{2}{*}{$\begin{array}{l}0.56 \\
(0.59)\end{array}$} & \multirow[t]{2}{*}{-} \\
\hline J-stat $3.15(d . f .=5)$ & & & & & & \\
\hline Chile (1992 Q1 - 2000 Q4) & \multirow[t]{2}{*}{$\begin{array}{l}0.85^{* * *} \\
(0.02)\end{array}$} & \multirow[t]{2}{*}{$\begin{array}{l}13.62^{* * *} \\
(0.77)\end{array}$} & \multirow[t]{2}{*}{$\begin{array}{l}0.58^{* *} \\
(1.08)\end{array}$} & \multirow{2}{*}{$\begin{array}{l}-1.90^{*} \\
(1.11)\end{array}$} & \multirow{2}{*}{$\begin{array}{l}-4.13 \\
(3.05)\end{array}$} & \multirow[t]{2}{*}{-} \\
\hline J-stat $4.11(d . f=7)$ & & & & & & \\
\hline New Zealand (1991 Q4 - 2000 Q4) & \multirow{2}{*}{$\begin{array}{l}0.89^{* * *} \\
(0.04)\end{array}$} & \multirow{2}{*}{$\begin{array}{l}7.64^{* * *} \\
(0.51)\end{array}$} & \multirow{2}{*}{$\begin{array}{l}3.32 \\
(2.11)\end{array}$} & \multirow{2}{*}{$\begin{array}{l}-3.37^{* * *} \\
(1.37)\end{array}$} & \multirow{2}{*}{$\begin{array}{l}1.19 \\
(1.76)\end{array}$} & \multirow[t]{2}{*}{-} \\
\hline J-stat $3.59(d . f .=5)$ & & & & & & \\
\hline Sweden (1993 Q3 - 2000 Q4) & $\begin{array}{l}0.87^{* * *} \\
(0.04)\end{array}$ & $\begin{array}{l}3.03^{* * *} \\
(0.68)\end{array}$ & $\begin{array}{l}-0.23 \\
(0.44)\end{array}$ & $\begin{array}{l}0.50 \\
(0.86)\end{array}$ & $\begin{array}{l}5.45^{* *} \\
(2.27)\end{array}$ & - \\
\hline \multicolumn{7}{|l|}{ J-stat $2.13(d . f .=6)$} \\
\hline & $\begin{array}{l}1.18^{* * *} \\
(0.06)\end{array}$ & $\begin{array}{l}3.34^{* * *} \\
(1.25)\end{array}$ & $\begin{array}{l}-1.09 \\
(1.38)\end{array}$ & $\begin{array}{l}-0.19 \\
(1.57)\end{array}$ & - & $\begin{array}{l}-5.02 \\
(2.26)\end{array}$ \\
\hline \multicolumn{7}{|l|}{ J-stat $1.68(d . f .=6)$} \\
\hline United Kingdom (1993 Q3 - 2000 Q4) & $\begin{array}{l}0.83^{* * *} \\
(0.09)\end{array}$ & $\begin{array}{l}5.95^{* * *} \\
(0.27)\end{array}$ & $\begin{array}{l}2.41^{*} \\
(1.18)\end{array}$ & $\begin{array}{l}-2.30^{*} \\
(1.18)\end{array}$ & $\begin{array}{l}2.25 \\
(1.73)\end{array}$ & - \\
\hline \multirow[t]{2}{*}{ J-stat $4.73(d . f .=9)$} & & & & & & \\
\hline & $\begin{array}{l}0.65^{* * *} \\
(0.06)\end{array}$ & $\begin{array}{l}6.04^{* * *} \\
(0.14)\end{array}$ & $\begin{array}{l}1.14 \\
(0.65)\end{array}$ & $\begin{array}{l}-1.86^{* *} \\
(0.64)\end{array}$ & - & $\begin{array}{l}0.09 \\
(0.45)\end{array}$ \\
\hline J-stat $5.38(d . f .=9)$ & & & & & & \\
\hline
\end{tabular}

Table 4: Parameter Estimates - Model with Policy "Contagion" 


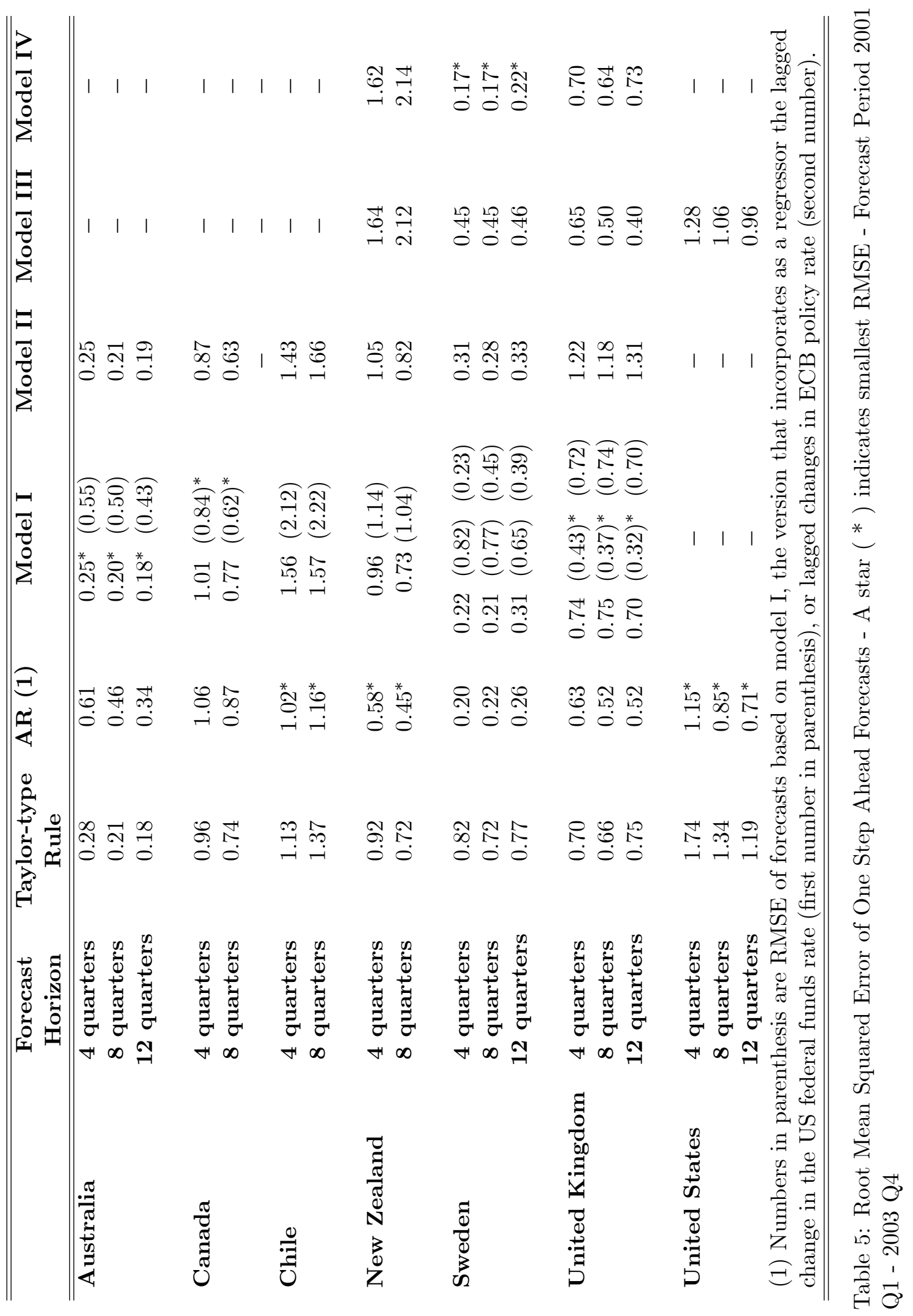




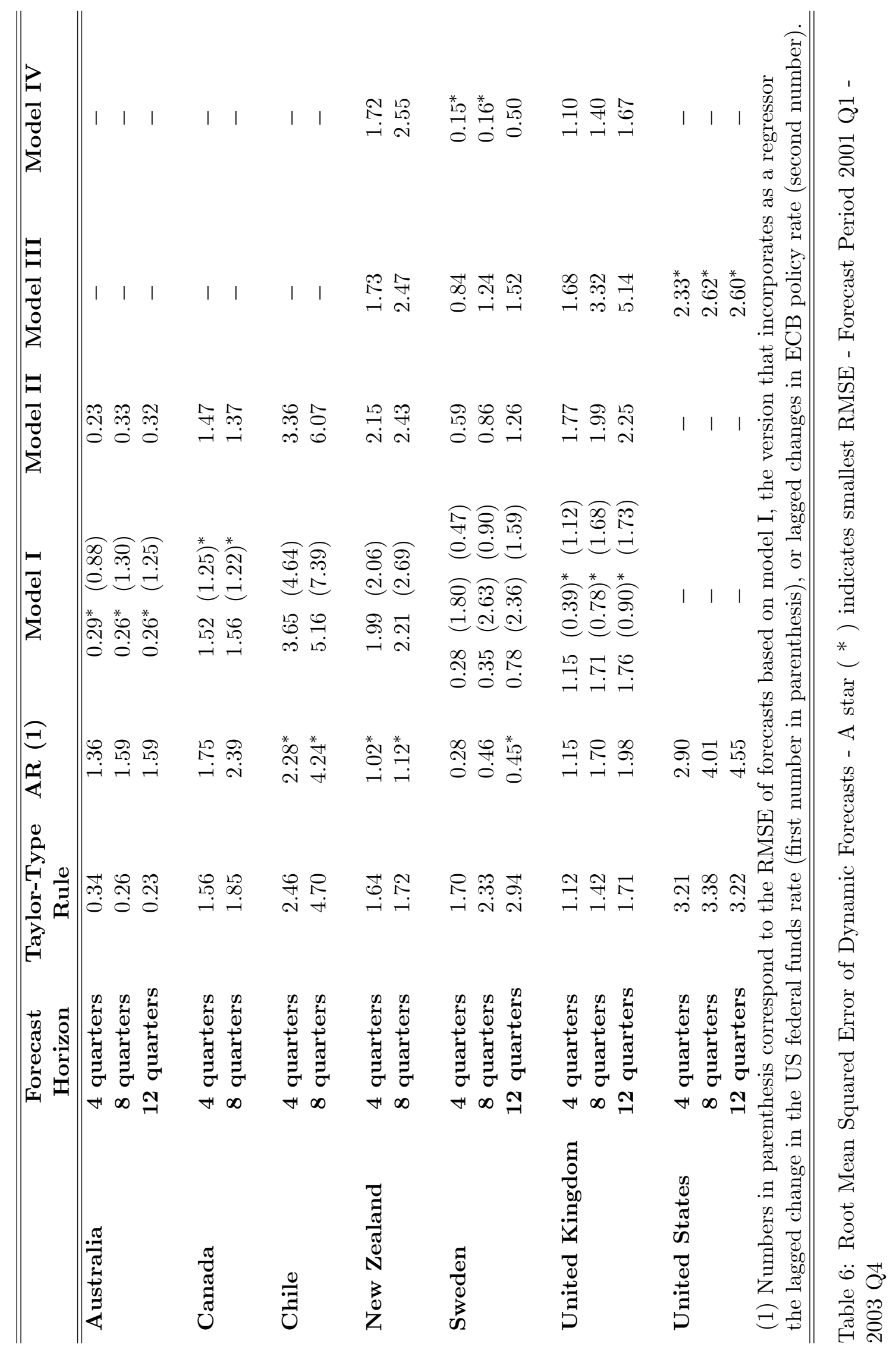

